\title{
Study of an argon dielectric barrier discharge reactor with atmospheric pressure for material treatment
}

\author{
Maryam Hosseinpour ${ }^{1} \cdot$ Akbar Zendehnam $^{1}$
}

Received: 18 September 2018 / Accepted: 16 December 2018 / Published online: 29 December 2018

(c) The Author(s) 2018

\begin{abstract}
In this study, effects of the variation in the dielectric barrier discharge's (DBD) gap distance and the nature of dielectric layers which cover both of the reactor electrodes on the electron density, mass fraction of excited argon atoms across the discharge gap, mean electron energy, ion and electron current density, and electron temperature are investigated at atmospheric pressure. In order to find the optimal reactor gap, the DBD's average power consumption is studied. The achievements show that when the value of dielectric constant is increased from 7.6 to 10 , discharge gap of $1 \mathrm{~mm}$ still demonstrates the maximum power consumption, which can be considered as the optimum discharge gap. To optimize the characteristics of one-dimensional modeling of DBD system for material treatment, various types of materials with different values of the permittivity [aluminum, glass (quartz) and silicon] are embedded in the discharge gap between the two electrodes. In this case, the reactor gap is changed from $0.5 \mathrm{~mm}$ to $2 \mathrm{~mm}$, while the dielectric constant of the dielectric layers which cover both of the metallic electrodes is assumed to be 10. Compared to the other examined materials, our numerical results illustrate that the treated material with higher value of the relative permittivity (silicon) has greater influences on the variations in the electron density, argon ion density and also total plasma current density than in the values of excited argon atom density, mass fraction of excited argon atoms and also average power consumption.
\end{abstract}

Keywords Dielectric barrier discharge simulation $\cdot$ Atmospheric pressure $\cdot$ Reactor gap $\cdot$ Relative permittivity $\cdot$ Surface treatment $\cdot$ Average power consumption

\section{Introduction}

To enhance the surface energy of such substrates as polymers or dielectrics, their surface should be activated by plasma treatment. Plasma treatment is one of the most versatile techniques in surface modification and growing such nanostructures as silicon nanoparticles on a surface [1-3]. The plasma is usually generated by ionization of a feed gas that produces positive and negative ions, energetic electrons, UV photons, along with active free radicals. Atmospheric plasma treatments are especially attractive due to the elimination of expensive vacuum equipment, easier handling of the samples and so on [4-8]. Therefore, in recent years, a lot of efforts have been directed into the development of nonthermal plasma reactors working at atmospheric pressure.

Maryam Hosseinpour

maryamhosseinpour35@yahoo.com

1 Department of Physics, Faculty of Science, Arak University, P.O. Box: 38156-8-8349, Arak, Iran
One promising technology for producing cold atmospheric plasmas (CAP) is based on the use of dielectric barrier discharge (DBD), sometimes referred to as a barrier discharge or a silent discharge, a type of discharge where at least one of the electrodes is covered with a dielectric material [2-9]. This dielectric layer acts as a current limiter and prevents the formation of an arc discharge. The electrical energy coupled into a DBD plasma is mainly transferred to energetic electrons, while the neutral gas remains closest to ambient temperatures. Cold atmospheric plasma (CAP) is known as non-thermal because it has electrons at a hotter temperature than the heavy particles that are at room temperature. Applications of CAP include sterilization of medical equipment, packaging in the food industry, wound healing, and such dental applications as dental caries, elimination of biofilms and bleaching [7-9]. DBD has many applications including: sterilization of living tissue, bacteria inactivation, surface treatment and activation, and excimer formation [4, 10-12]. The width of the discharge gap can range from less than $0.1 \mathrm{~mm}$ to about $100 \mathrm{~mm}$, and applied frequency from below 
line frequency to several MHz. Depending on the composition of the working gas, the voltage and the frequency excitation, the discharge can be either filamentary or glow. Moreover, one key issue of DBD employed for material processing is the distribution of micro-discharges as a function of time over the dielectric surface [1].

In order to produce powerful, efficient and mercury-free UV sources, researchers have modeled a promising DBD lamp for UV production. This lamp was usually made of silica glass chamber, including the gas or gas mixture at a pressure between $10^{4}$ and $10^{5} \mathrm{~Pa}$ with outer electrodes [13]. Recently, a DBD system with additional porous ceramic segment as a flowing water guide has been introduced to purify the polluted water [14]. The significance of the investigation of DBD's characteristics appears especially in medical applications [12-15]. In order to optimize the design of a DBD reactor, it is important to calculate the power consumed over a wide range of discharge conditions [16-18]. To clarify that there is an optimal discharge gap for material treatment; researchers have investigated the influences of varying the applied voltage and discharge gap on the power consumption using a simplified model of the reactor equivalent electrical circuit [19]. Many works have been focused on the simulation of DBDs at atmospheric pressure. For example, Sohbatzadeh et al. studied time-dependent one-dimensional model of a DBD in a nitrogen-oxygen-water vapor mixture at atmospheric pressure using COMSOL Multiphysics [20]. One of the most important parameters in nanotechnology and thin films is surface and its roughness, since it is the first interface of material which may interact with other materials and with environment. More recently, atmospheric pressure plasma treatments, such as a DBD in helium [21] and a homogeneous DBD in nitrogen [22], were used for modification of polycarbonate (PC) surface properties. Nastuta et al. used two different configurations of atmospheric DBD plasma for the surface modification of polyethylene terephthalate (PET) and polyethylene with $\mathrm{TiO}_{2}$ additives [23]. In addition, some early papers have experimentally studied the interaction of the plasma plume emitted by an atmospheric pressure plasma jet with different substrates, i.e., a dielectric and a metal substrate [24, 25]. In our early work, the influence of non-thermal plasma jet (He and Ar) was studied to improve the antibacterial activity, surface roughness and hydrophilic property of Ag thin films [26]. However, as far as we know, none of previous studies have given comprehensive numerical insight into finding the optimal DBD reactor gap when the effects of variations in the nature of dielectric layers or gap distance on the properties of the system are studied. Employing COMSOL Multiphysics v5.0 software, the present work investigates the design and analysis of a DBD reactor with both of the circular flat electrodes covered with dielectric materials to optimize various characteristics of the proposed system, such as average power consumption, for surface processing. Indeed, the main aim of the research described in this work is to obtain an optimal value of reactor gap for average power consumption in the proposed DBD system where different materials are treated. Therefore, the work is organized as follows: A detailed description of the DBD structure without any materials in the gap region and the corresponding numerical analysis are presented in "Design Guidelines for the DBD without any material in the discharge gap" section. Please note that in "Design Guidelines for the DBD without any material in the discharge gap" section, two structural parameters of the DBD system, the nature of the dielectric layers that cover the metallic electrodes and also the reactor gap are varied. The influence of the presence of different materials with various relative permittivities on the characteristics of one-dimensional modeling of DBD is investigated in "Design guidelines for the DBD including materials with different dielectric constant in the discharge gap" section. In this section, the reactor gap is the only structural parameter of the DBD which is assumed to vary (from $0.5 \mathrm{~mm}$ to $2 \mathrm{~mm}$ ); however, the dielectric constant of dielectric layers is fixed on 10. Finally, conclusion is explained in "Conclusions" section. Numerical results show the DBD with dielectric constant of 10 for dielectric layers (without any materials across the discharge gap) offers the power consumptions higher than the DBD with dielectric constant 7.6, particularly in the gap distances of $0.5 \mathrm{~mm}$ and $1 \mathrm{~mm}$. Moreover, compared to the other materials [aluminum and glass (quartz)], silicon (the material with higher value of relative permittivity) has greater effect on the variations in the electron density, argon ion density and also total plasma current density than in the values of excited argon atom density, mass fraction of excited argon atoms and power consumption as the reactor gap is varied from $0.5 \mathrm{~mm}$ to $2 \mathrm{~mm}$.

\section{Simulation results and discussions}

\section{Design guidelines for the DBD without any material in the discharge gap}

COMSOL Multiphysics v5.0 software is employed to model a DBD reactor with both of the circular plane electrodes covered by dielectric layers (with two different values of dielectric constant, which are assumed to be 7.6 and 10 , respectively). In our modeling technique, it is supposed that the DBD system is designed in one dimension due to the fact that reactor gap $(\mathrm{mm})$ is much smaller than the plate area of electrodes $\left(\mathrm{cm}^{2}\right)$ [27]. Please note that in the following sections, the discharge volume of the simulated DBDs is filled with argon gas (the gas pressure is $1 \times 10^{5} \mathrm{~Pa}$ ) [28]. The initial value for the electron density is assumed to be $10^{6} 1 / \mathrm{m}^{3}$ which refers to the fact that the gap is truly acting 
as an insulator initially, and the gas temperature and also the reduced electron mobility are supposed to be $400 \mathrm{k}$ and $1 \times 10^{25}$ [1/v.s.m], respectively. In the following "Evaluations of the electron densities across the discharge domain," "Evaluations of the mass fraction of excited argon atoms (Ar*) created in the discharge domain," "Evaluations of the electron temperature and the mean electron energy in the discharge domain," "Evaluations of the total plasma current density in the discharge domain" and "Calculations of the DBD's average power consumption for determination of the optimal reactor gap without the presence of any material in the gap region" sections, the effects of variations in both of the reactor gap (from 0.5 to $2 \mathrm{~mm}$; with step $0.5 \mathrm{~mm}$ ) and the nature of the dielectric layers that cover the metallic electrodes on the properties of our proposed DBD system are studied, while there is no material for treatment in the discharge gap. Moreover, the values of the applied voltage, frequencies, diameter of the round electrodes and thickness of the dielectric layers which cover both of the reactor electrodes are assumed to be constant and are introduced in Table 1. As can be seen in Table 1, the applied voltage amplitude and frequency are assumed to be $750 \mathrm{~V}$ and $50 \mathrm{kHz}$, respectively, which are greater than $500 \mathrm{~V}$ and $10 \mathrm{kHz}$ in [29]. The reactions of electron impact with argon atoms are depicted in Table 2. The surface reactions are also shown in Table 3. The collision cross sections and electron energy for elastic and ionization reactions $R_{1}$, and $R_{2}, R_{4}$ and $R_{5}$ are, respectively, depicted in Tables 4 and 5 .

Figure 1a illustrates the one-dimensional (1D) discharge geometry of the simulated DBD, and the three-dimensional

Table 1 Values of applied voltage, frequency, diameter of the electrodes and thickness of the dielectric layers

\begin{tabular}{ll}
\hline Constant parameters & Value \\
\hline Frequency & $50 \times 10^{3}(\mathrm{~Hz})$ \\
Applied voltage & $-750 \sin \omega \mathrm{t}(\mathrm{V})$ \\
Diameter of the electrodes & $0.1(\mathrm{~m})$ \\
Thickness of the dielectric material & $1.5(\mathrm{~mm})$ \\
\hline
\end{tabular}

Table 3 Surface reactions [27, 28, 30]

\begin{tabular}{llll}
\hline Reaction & Formula & Type & $\begin{array}{l}\text { Sticking } \\
\text { coeffi- } \\
\text { cient }\end{array}$ \\
\hline $\mathrm{R}_{1}$ & $\mathrm{e}+\mathrm{Ar} \Rightarrow \mathrm{e}+\mathrm{Ar}$ & Elastic & 1 \\
$\mathrm{R}_{2}$ & $\mathrm{e}+\mathrm{Ar} \Rightarrow \mathrm{e}+\mathrm{Ar} *$ & Excitation & 1 \\
\hline
\end{tabular}

(3D) structure of our designed DBD is also demonstrated in Fig. 1b. The distance between the points B and C corresponds to the discharge domain. The boundaries are consequently at these points. Point $\mathrm{A}$ is connected to the voltage source, and point $\mathrm{D}$ is supposed to be fixed at 0 (the electrically grounded plate).

Considering a Dirichlet boundary condition on the outside of the dielectrics, the plasma is driven by a sinusoidal alternating voltage-power supply with a frequency of $50 \mathrm{kHz}$ (Table 1). When the applied voltage which must exceed the breakdown voltage of the gases is attained, the gases lose their dielectric properties and turn into conductors [31]. Based on the electric equivalent network model, the system equations governing the discharge can be easily obtained in a simplified manner to investigate and examine the electrical behavior of a DBD [32-34]. In the case of the parallel plate configuration of DBD system, the equations used to estimate the real value of equivalent capacitances of the dielectric barrier $\left(C_{\mathrm{d}}\right)$ and discharge gas gap $\left(C_{\mathrm{g}}\right)$, are, respectively, given as [34]:

$C_{\mathrm{g}}=\frac{\varepsilon_{0} k_{1} A}{d_{\mathrm{g}}}$

$C_{\mathrm{d}}=\frac{\varepsilon_{0} k_{2} A}{d_{\mathrm{b}}}$

where $k_{1}$ is the dielectric constant of the working media used in the gas discharge, $k_{2}$ is the dielectric constant of the used dielectric barrier material, $A$ is overall discharge area;
Table 2 The reactions of electron with argon gas (excited argon atoms Ar*: all of the excited atoms in $4 \mathrm{~s}$ level, argon atom Ar, singly ionized argon atom $\mathrm{Ar}^{+}$) [30]

\begin{tabular}{lllll}
\hline Reaction & Formula & Type & $\Delta E(\mathrm{ev})$ & $\begin{array}{l}\text { Rate con- } \\
\text { stant }\left(\mathrm{m}^{3} / \mathrm{s} .\right. \\
\mathrm{mol})\end{array}$ \\
\hline$R_{1}$ & $\mathrm{e}+\mathrm{Ar} \Rightarrow \mathrm{e}+\mathrm{Ar}$ & Elastic & $m / M=0.0000136$ & - \\
$R_{2}$ & $\mathrm{e}+\mathrm{Ar} \Rightarrow \mathrm{e}+\mathrm{Ar} *$ & Excitation & 11.5 & - \\
$R_{3}$ & $\mathrm{e}+\mathrm{Ar} \Rightarrow \mathrm{e}+\mathrm{Ar}$ & Superelastic & -11.5 & - \\
$R_{4}$ & $\mathrm{e}+\mathrm{Ar} \Rightarrow 2 \mathrm{e}+\mathrm{Ar}^{+}$ & Ionization & 15.8 & - \\
$R_{5}$ & $\mathrm{e}+\mathrm{Ar} * 2 \mathrm{e}+\mathrm{Ar}^{+}$ & Ionization & 4.427 & - \\
$R_{6}$ & $\mathrm{Ar}+\mathrm{Ar} \Rightarrow \mathrm{e}+\mathrm{Ar}+\mathrm{Ar}^{+}$ & Penning ionization & - & $3.3734 \times 10^{8}$ \\
$R_{7}$ & $\mathrm{Ar}+\mathrm{Ar} \Rightarrow \mathrm{Ar}+\mathrm{Ar}$ & Metastable quenching & - & 1807 \\
\hline
\end{tabular}


Table 4 Collision cross sections and electron energy for elastic and ionization reactions $\left(R_{1}\right)$ in Table $2[27,28,30]$

\begin{tabular}{|c|c|c|c|}
\hline \multicolumn{4}{|c|}{$R_{1}: \mathrm{e}+\mathrm{Ar} \Rightarrow \mathrm{e}+\mathrm{Ar}$} \\
\hline Electron energy & $\begin{array}{l}\text { Collision } \\
\text { cross sections } \\
\left(\times 10^{-19}\right)\end{array}$ & Electron energy & $\begin{array}{l}\text { Collision } \\
\text { cross sections } \\
\left(\times 10^{-19}\right)\end{array}$ \\
\hline 0.00 & 0.7500 & 2.8 & 0.3800 \\
\hline 0.001 & 0.7500 & 3 & 0.4100 \\
\hline 0.002 & 0.7100 & 3.3 & 0.4500 \\
\hline 0.003 & 0.6700 & 3.6 & 0.4900 \\
\hline 0.005 & 0.6100 & 4 & 0.5400 \\
\hline 0.007 & 0.5400 & 4.5 & 0.6100 \\
\hline 0.0085 & 0.5050 & 5 & 0.6700 \\
\hline 0.01 & 0.4600 & 6 & 0.8100 \\
\hline 0.015 & 0.3750 & 7 & 0.9600 \\
\hline 0.02 & 0.3250 & 8 & 1.170 \\
\hline 0.03 & 0.2500 & 10 & 1.500 \\
\hline 0.04 & 0.2050 & 12 & 1.450 \\
\hline 0.05 & 0.1730 & 15 & 1.370 \\
\hline 0.07 & 0.1130 & 17 & 1.100 \\
\hline 0.1 & 0.05900 & 20 & 0.9200 \\
\hline 0.12 & 0.04000 & 25 & 0.6800 \\
\hline 0.15 & 0.02300 & 30 & 0.5500 \\
\hline 0.17 & 0.01600 & 50 & 0.3200 \\
\hline 0.2 & 0.01030 & 75 & 0.2150 \\
\hline 0.25 & 0.009100 & 100 & 0.1600 \\
\hline 0.3 & 0.01530 & 150 & 0.1100 \\
\hline 0.35 & 0.02350 & 200 & 0.08800 \\
\hline 0.4 & 0.03300 & 300 & 0.06000 \\
\hline 0.5 & 0.05100 & 500 & 0.03700 \\
\hline 0.7 & 0.08600 & 700 & 0.02600 \\
\hline 1 & 0.1380 & 1000 & 0.01700 \\
\hline 1.2 & 0.1660 & 1500 & 0.009800 \\
\hline 1.3 & 0.1820 & 2000 & 0.006600 \\
\hline 1.5 & 0.2100 & 3000 & 0.003500 \\
\hline 1.7 & 0.2300 & 5000 & 0.001500 \\
\hline 1.9 & 0.2500 & 7000 & 0.0008800 \\
\hline 2.1 & 0.2800 & 10,000 & 0.0004900 \\
\hline 2.2 & 0.2900 & $1,000,000$ & 0.0004900 \\
\hline 2.5 & 0.3300 & & \\
\hline
\end{tabular}

$\varepsilon_{0}=8.854 \times 10^{-12} \frac{c^{2}}{\mathrm{Nm}^{2}}$, and $d_{\mathrm{b}}$ and $d_{\mathrm{g}}$ are the thickness of the dielectric barrier and discharge gap, respectively. The gas voltage $\left(V_{\mathrm{g}}(t)\right)$, which is the response of plasma to the applied voltage, is calculated from Eq. 3 [34]:

$V_{\mathrm{g}}(t)=V_{\mathrm{e}}(t) \frac{C_{\mathrm{d}}}{C_{\mathrm{d}}+C_{\mathrm{g}}}$

where $V_{\mathrm{e}}(t)$ signifies the external excitation voltage.
Figure 2 shows the $V-I$ characteristics of the electrical discharge across the gap when the dielectric constant of dielectric layer is 10 and the gap distance is varied from $0.5 \mathrm{~mm}$ to $2 \mathrm{~mm}$. In this figure, the change in current depicts breakdown of the gas gap. As a result, the breakdown is started when the gas voltage reaches above the breakdown voltage which for various gap distances: $0.5 \mathrm{~mm}, 1 \mathrm{~mm}, 1.5 \mathrm{~mm}$ and $2 \mathrm{~mm}, V_{\mathrm{g}}(t)$ is obtained $576.9 \mathrm{~V}, 299.87 \mathrm{~V}, 681.77 \mathrm{~V}$ and $428.43 \mathrm{~V}$, respectively. Moreover, the maximum of discharge current in different gap distances $0.5 \mathrm{~mm}, 1 \mathrm{~mm}, 1.5 \mathrm{~mm}$ and $2 \mathrm{~mm}$ is $62.52 \mathrm{~mA}, 66.57 \mathrm{~mA}, 54.29 \mathrm{~mA}$ and $49.39 \mathrm{~mA}$, respectively.

\section{Evaluations of the electron densities across the discharge domain}

Spatiotemporal evolutions of the electron density versus the gap spacing are depicted in Fig. 3 when the dielectric constant of dielectric layers is 7.6 and the reactor gap is varied from $0.5 \mathrm{~mm}$ to $2 \mathrm{~mm}$. The evolutions for the electron density across the reactor gap for different dielectric layers (dielectric constant 7.6 and 10) are shown in Fig. 4. It can be seen in Fig. 3b, c that after approximately 4 RF cycles, the electron density in the discharge gap illustrates a periodic steady state when the reactor gap is $1 \mathrm{~mm}$ or $1.5 \mathrm{~mm}$, respectively.

According to the mechanism of a DBD system, electrons created via electron impact ionization move toward one of the dielectric plates, in the opposite direction to the electric field. An equal number of ions are generated during electron impact ionization, as well. The ions rush toward the opposite dielectric plate in the same direction as the electric field. As a result, surface charge densities with opposite sign localized on both dielectric plates at the interface dielectric/plasma led to the breakdown electric filed. This surface charge strongly depends on such parameters as the nature of the dielectric [13]. Accordingly, as dielectric constant of the dielectric layers is increased to 10 , the electron density rises remarkably for all of the gap distances. Varying the reactor gap from $1.5 \mathrm{~mm}$ to $2 \mathrm{~mm}$ (Fig. $2 \mathrm{~d}$ ) leads to a disturbance in the plot of electron density. This is due to the fact that by increasing the reactor gap to $2 \mathrm{~mm}$, the produced plasma in the discharge region becomes unstable. According to Fig. 4, the corresponding electron density plots show approximately the same alternative behavior as the gap is varied from $0.5 \mathrm{~mm}$ to $2 \mathrm{~mm}$.

From Fig. 4, it clearly illustrates that by increasing the reactor gap from $0.5 \mathrm{~mm}$ to $2 \mathrm{~mm}$, the density of electrons rises considerably. This is due to the fact that as the reactor gap is increased, the possibility of existence of electrons created via electron impact ionization near to the dielectric layers which cover the metallic electrodes is decreased. This leads to the reduction in the recombination of electrons 
Table 5 Collision cross sections and electron energy for elastic and ionization reactions $R_{2}, R_{4}, R_{5}$ introduced in Table 2 [27-30]

\begin{tabular}{|c|c|c|c|c|c|}
\hline \multicolumn{2}{|c|}{$R_{2}: \mathrm{e}+\mathrm{Ar} \Rightarrow \mathrm{e}+\mathrm{Ar}^{*}$} & \multicolumn{2}{|c|}{$R_{4}: \mathrm{e}+\mathrm{Ar} \Rightarrow 2 \mathrm{e}+\mathrm{Ar}^{+}$} & \multicolumn{2}{|c|}{$R_{5}: \mathrm{e}+\mathrm{Ar}^{*} \Rightarrow 2 \mathrm{e}+\mathrm{Ar}^{+}$} \\
\hline Electron energy & $\begin{array}{l}\text { Collision cross sections } \\
\left(\times 10^{-19}\right)\end{array}$ & Electron energy & $\begin{array}{l}\text { Collision cross sections } \\
\left(\times 10^{-19}\right)\end{array}$ & Electron energy & $\begin{array}{l}\text { Collision cross } \\
\text { sections }\left(\times 10^{-19}\right)\end{array}$ \\
\hline 0.00 & 0.00 & 0.00 & 0.00 & 0.00 & 0.00 \\
\hline 11.50 & 0.00 & 15.80 & 0.00 & 4.427 & 0.00 \\
\hline 12.70 & 0.00700 & 16.00 & 0.002020 & 4.628 & 0.1849 \\
\hline 13.70 & 0.0141 & 17.00 & 0.01340 & 5.00 & 0.3100 \\
\hline 14.70 & 0.02280 & 18.00 & 0.02940 & 6.00 & 0.5800 \\
\hline 15.90 & 0.03800 & 20.00 & 0.06300 & 7.00 & 0.6900 \\
\hline 16.50 & 0.04800 & 22.00 & 0.09300 & 8.00 & 0.7600 \\
\hline 17.50 & 0.06100 & 23.75 & 0.1150 & 9.00 & 0.8000 \\
\hline 18.50 & 0.07500 & 25.00 & 0.1300 & 10.00 & 0.8200 \\
\hline 19.90 & 0.09200 & 26.50 & 0.1450 & 11.50 & 0.8350 \\
\hline 22.20 & 0.1170 & 30.00 & 0.1800 & 15.50 & 0.7800 \\
\hline 24.70 & 0.1330 & 32.50 & 0.1990 & 20.00 & 0.7000 \\
\hline 27.00 & 0.1420 & 35.00 & 0.2170 & 30.00 & 0.5400 \\
\hline 30.00 & 0.1440 & 37.50 & 0.2310 & 50.00 & 0.3800 \\
\hline 33.00 & 0.1410 & 40.00 & 0.2390 & 100.00 & 0.2050 \\
\hline 35.30 & 0.1340 & 50.00 & 0.2530 & 200.00 & 0.1200 \\
\hline 42.00 & 0.1250 & 55.00 & 0.2600 & 1000.00 & 0.03500 \\
\hline 48.00 & 0.1160 & 100.00 & 0.2850 & $10,000.00$ & 0.006100 \\
\hline 52.00 & 0.1110 & 150.00 & 0.2520 & $1,000,000.00$ & 0.001080 \\
\hline 70.00 & 0.09400 & 200.00 & 0.2390 & $10,000,000.00$ & 0.001080 \\
\hline 100.00 & 0.07600 & 300.00 & 0.2000 & & \\
\hline 150.00 & 0.06000 & 500.00 & 0.1450 & & \\
\hline 200.00 & 0.05050 & 700.00 & 0.1150 & & \\
\hline 300.00 & 0.03950 & 1000.00 & 0.08600 & & \\
\hline 500.00 & 0.02800 & 1500.00 & 0.06400 & & \\
\hline 700.00 & 0.02250 & 2000.00 & 0.05200 & & \\
\hline 1000.00 & 0.01770 & 3000.00 & 0.03600 & & \\
\hline 1500.00 & 0.01360 & 5000.00 & 0.02400 & & \\
\hline 2000.00 & 0.01100 & 7000.00 & 0.01800 & & \\
\hline 3000.00 & 0.008300 & $100,000.00$ & 0.01350 & & \\
\hline 5000.00 & 0.0005800 & $1,000,000.00$ & 0.01350 & & \\
\hline 7000.00 & 0.0004500 & & & & \\
\hline $10,000.00$ & 0.0003500 & & & & \\
\hline $1,000,000.00$ & 0.0003500 & & & & \\
\hline
\end{tabular}

coming from the plasma with positive argon ions or excited argon atoms which are around the surface of dielectric layer.

\section{Evaluations of the mass fraction of excited argon atoms $\left(A r^{*}\right)$ created in the discharge domain}

Figure 5 shows the mass fraction of Ar* produced in the discharge region for the proposed DBD with dielectric constant 7.6 as the gap is varied from $0.5 \mathrm{~mm}$ to $2 \mathrm{~mm}$. Accordingly, increasing the reactor gap causes a delay time to form mass fraction of Ar*. As an example, when the gap is $0.5 \mathrm{~mm}$, the startup cycle can be observed at $0.5 \mathrm{~ms}$ (see Fig. 5a).
Additionally, the discharge reaches a periodic steady-state solution after only one RF cycle (Fig. 5a). However, this startup cycle for the gaps of $1 \mathrm{~mm}, 1.5 \mathrm{~mm}$ and $2 \mathrm{~mm}$ occurs for $1 \mathrm{~ms}, 2 \mathrm{~ms}$ and $2 \mathrm{~ms}$, respectively. Hence, the discharge in these gaps reaches a periodic steady state after two RF cycles (Fig. 5b-d). The plots of mass fraction of excited argon atoms as a function of gap distance are depicted in Fig. 6 for the DBDs with dielectric constant 7.6 and 10, respectively. As shown in this figure, we can see that the mass fraction of Ar* decreases almost linearly when the reactor gap increases from $0.5 \mathrm{~mm}$ to $2 \mathrm{~mm}$. Additionally, the mass fraction of Ar* reduces remarkably for the 
Fig. 1 a The 1D discharge geometry of the simulated $\mathrm{DBD}, \mathbf{b}$ the $3 \mathrm{D}$ structure of the designed DBD

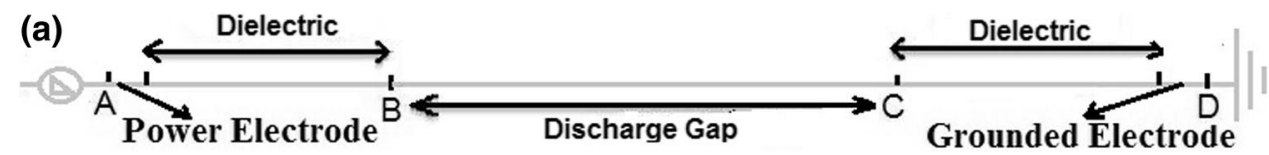

(b)

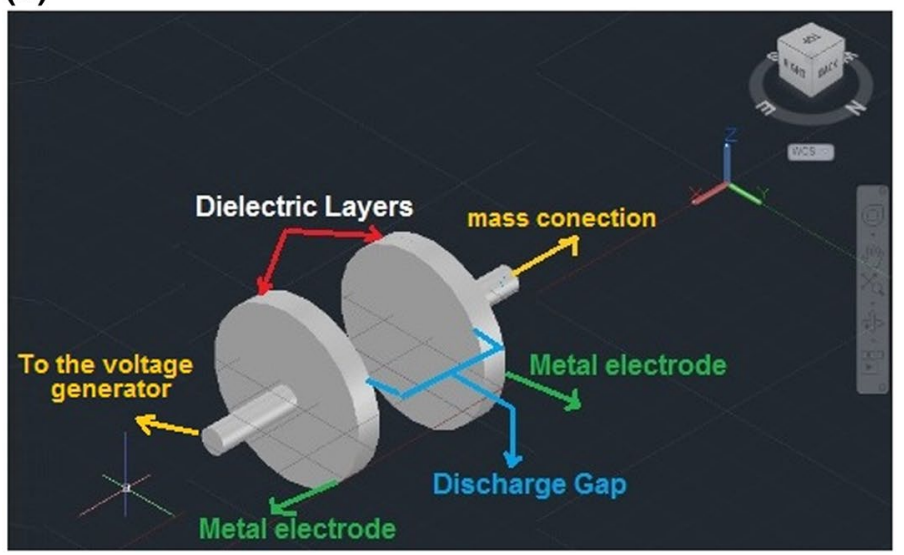

dielectric layers with dielectric constant of 10 , as the reactor gap distance increases to $2 \mathrm{~mm}$. This is due to the fact that the excited argon atoms have a much longer lifetime in the gap than the electrons or ions. Moreover, the excited argon atoms need to obtain lower value of ionization potential (about $20 \mathrm{eV}$ ) to reach the state of singly ionized argon atom $\mathrm{Ar}^{+}$, compared to the argon atoms in the stable state with ionization potential of $36 \mathrm{eV}$. As can be seen in Fig. 4, varying the reactor gap from $0.5 \mathrm{~mm}$ to $2 \mathrm{~mm}$ results in the remarkable increment of electron density (shown in Fig. 4, for example from $7 \times 10^{17} 1 / \mathrm{m}^{3}$ to $14 \times 10^{17} 1 / \mathrm{m}^{3}$ for the dielectric layers with dielectric constant 10$)$. Therefore, more number of excited argon atoms in the discharge domain can obtain around $20 \mathrm{eV}$ energy from these electrons to produce argon ions; hence, the mass fraction of Ar* reduces. Such linear decrement can be seen more considerably for the DBD with dielectric layers with higher values of dielectric constant which is 10 .

\section{Evaluations of the electron temperature and the mean electron energy in the discharge domain}

In Fig. 7, time evolutions of the electron temperature are illustrated for the DBD with dielectric constant 7.6 as the gap is $0.5 \mathrm{~mm}$ and $2 \mathrm{~mm}$, respectively. The electron temperature grows and reduces corresponding to each discharge event. According to Fig. 8, it greatly remarks that the electron temperature plots of the two DBDs with different values of dielectric constant (7.6 and 10) demonstrate approximately the same linear behavior as the gap is varied from $0.5 \mathrm{~mm}$ to $2 \mathrm{~mm}$. This is a consequence of the fact that the reactor gap cannot affect the electron temperature remarkably. Additionally, the DBD with dielectric constant 10 possesses the higher values of electron temperature (about $4.5 \mathrm{eV}$ ) compared to the DBD with the lower dielectric constant 7.6, which is nearly $4 \mathrm{eV}$. However, we can see that variation in the nature of dielectric layers cannot influence noticeably the electron temperature (the increment is only $0.5 \mathrm{eV})$.

Spatiotemporal simulation results of mean electron energy are displayed in Fig. 9 for the DBD with dielectric constant 7.6 for the gap distances of $0.5 \mathrm{~mm}$ and $2 \mathrm{~mm}$. Moreover, the corresponding plots as a function of the reactor gap are illustrated in Fig. 10. Accordingly, it can be seen that not only the electron temperature (Fig. 8) but also mean electron energy plots (Fig. 10) show approximately the same behavior.

Figure 10 also implies that variation in the nature of the dielectric layer which covers both of the electrodes cannot influence the mean electron energy significantly. This is a consequence of the fact that the DBD with dielectric constant of 10 offers mean electron energy about $6.5 \mathrm{eV}$ for all of the examined gaps (from $0.5 \mathrm{~mm}$ up to $2 \mathrm{~mm}$ ); however, the other DBD possesses the values of $6 \mathrm{eV}$.

\section{Evaluations of the total plasma current density in the discharge domain}

In Figs. 11 and 12, the current density of electrons and ions for the DBD with dielectric constant 7.6 in the gap distances of $0.5 \mathrm{~mm}$ and $2 \mathrm{~mm}$ is depicted, respectively. As expected, in $1 \mathrm{D}$ simulation of a DBD reactor, the total current density is constant across the gap at any point in time (see Fig. 13). The electron current density plots in Fig. 14 show approximately the same alternative behavior as the gap is varied from $0.5 \mathrm{~mm}$ to $2 \mathrm{~mm}$. Compared to Fig. 4, variation in the 
(a)

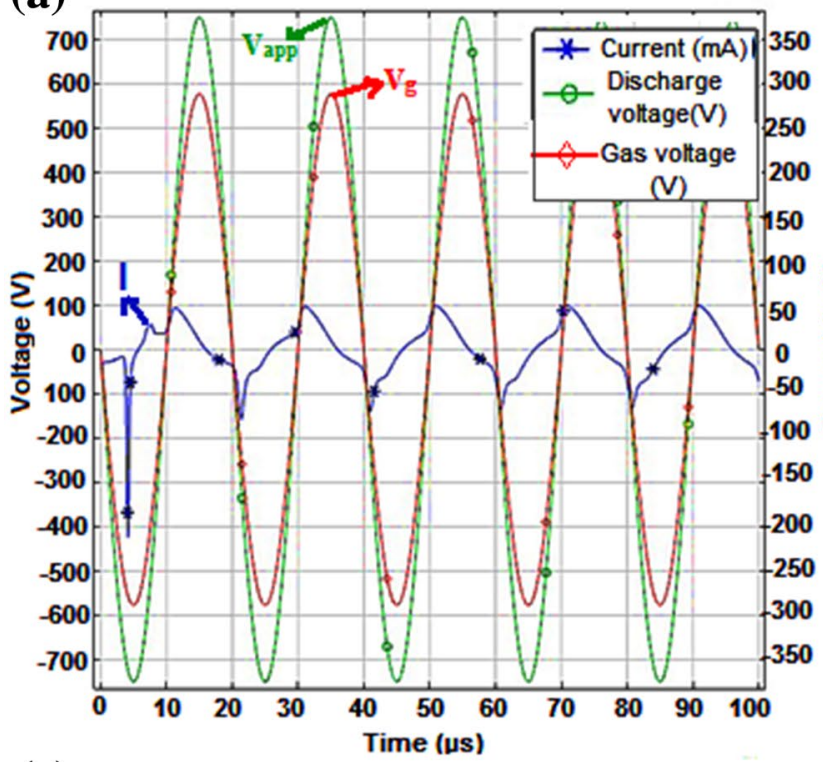

(c)

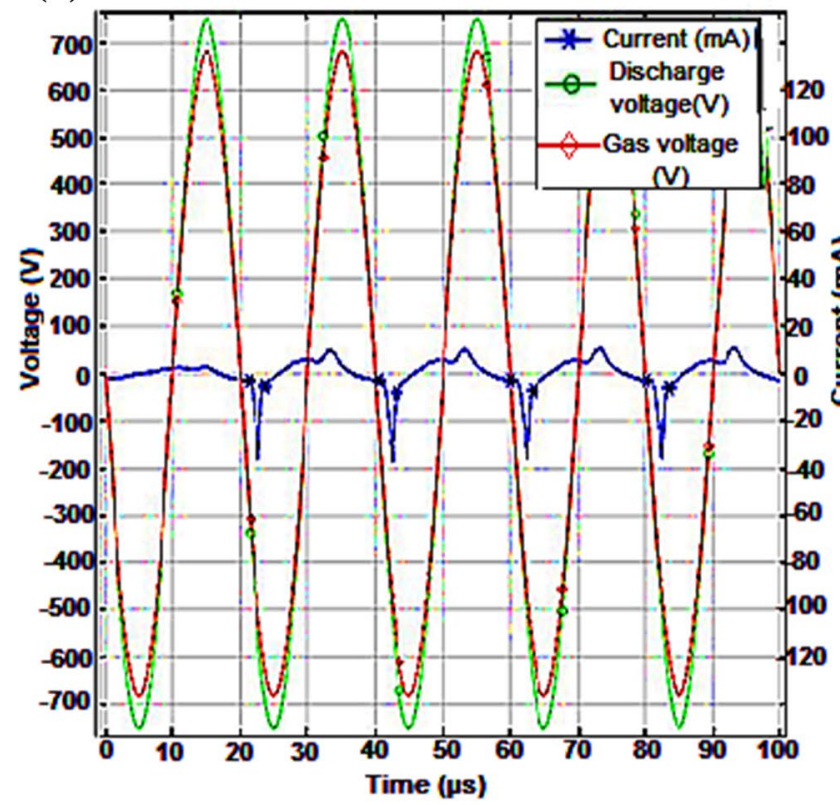

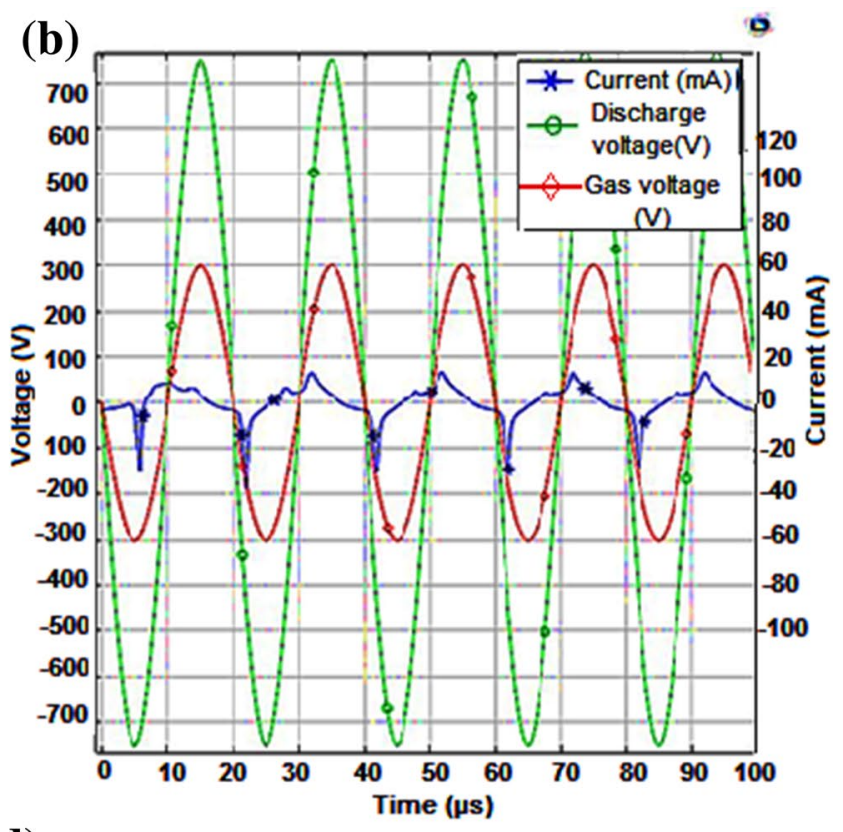

(d)

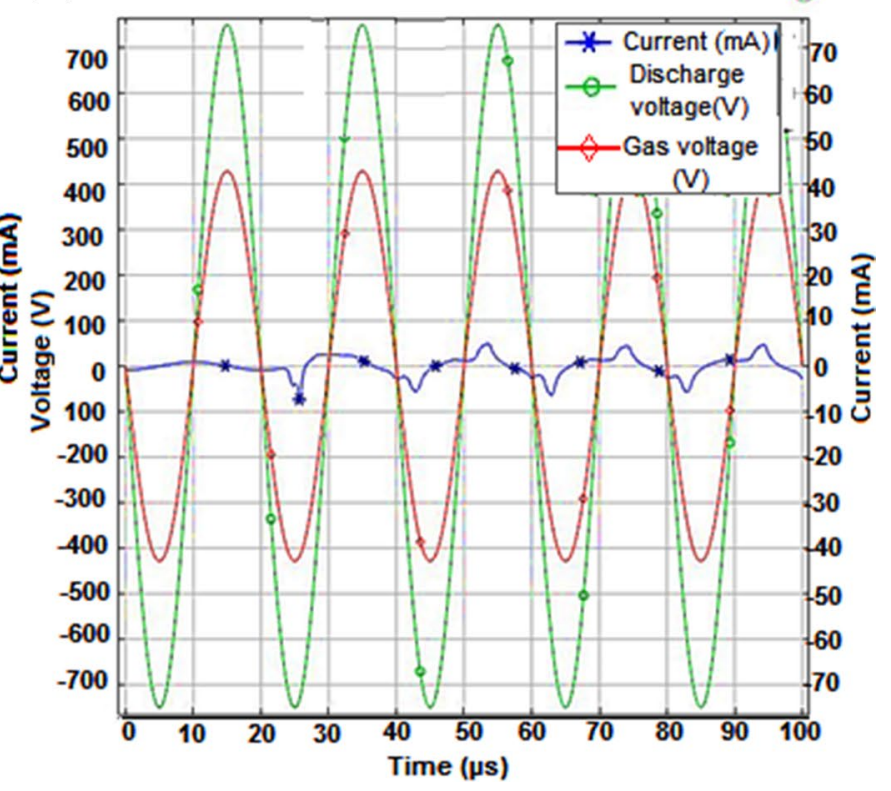

Fig. 2 Current-voltage waveform and the gas voltage for discharge with the applied voltage amplitude of $750 \mathrm{~V}$ and frequency $50 \mathrm{kHz}$ for the DBD with dielectric constant 10 for various gap distances: a $0.5 \mathrm{~mm}, \mathbf{b} 1 \mathrm{~mm}, \mathbf{c} 1.5 \mathrm{~mm}$ and $\mathbf{d} 2 \mathrm{~mm}$

electron density and electron current density can be considered similarly as the gap is increased. According to simulation results, it can be seen that the increase in the reactor gap from $0.5 \mathrm{~mm}$ up to $1.5 \mathrm{~mm}$ leads to the variation in the electron and ion current densities approximately within the range of $4-10 \mathrm{~A} / \mathrm{m}^{2}$ for both of the dielectric constants 7.6 and 10. However, in the gap of $2 \mathrm{~mm}$ for the DBD with dielectric constant 10 , the electron current density increases even more than $14 \mathrm{~A} / \mathrm{m}^{2}$, while the maximum values of ion current density cannot exceed $14 \mathrm{~A} / \mathrm{m}^{2}$ (see Figs. 14 and 15). For example, the DBD with dielectric constant 10 at the gap $2 \mathrm{~mm}$ offers about $18 \mathrm{~A} / \mathrm{m}^{2}$ for the electron current density; however, the value of ion current density cannot exceed $13 \mathrm{~A} / \mathrm{m}^{2}$. Total plasma current density against the reactor gap for different values of dielectric constant is also depicted in Fig. 16. 
Fig. 3 Spatiotemporal evolutions of the electron density (1/ $\mathrm{m}^{3}$ ) versus the gap spacing for DBD with dielectric constant 7.6 when reactor gap is variable: a $0.5 \mathrm{~mm}$, b $1 \mathrm{~mm}$, c $1.5 \mathrm{~mm}$ and $\mathbf{d} 2 \mathrm{~mm}$
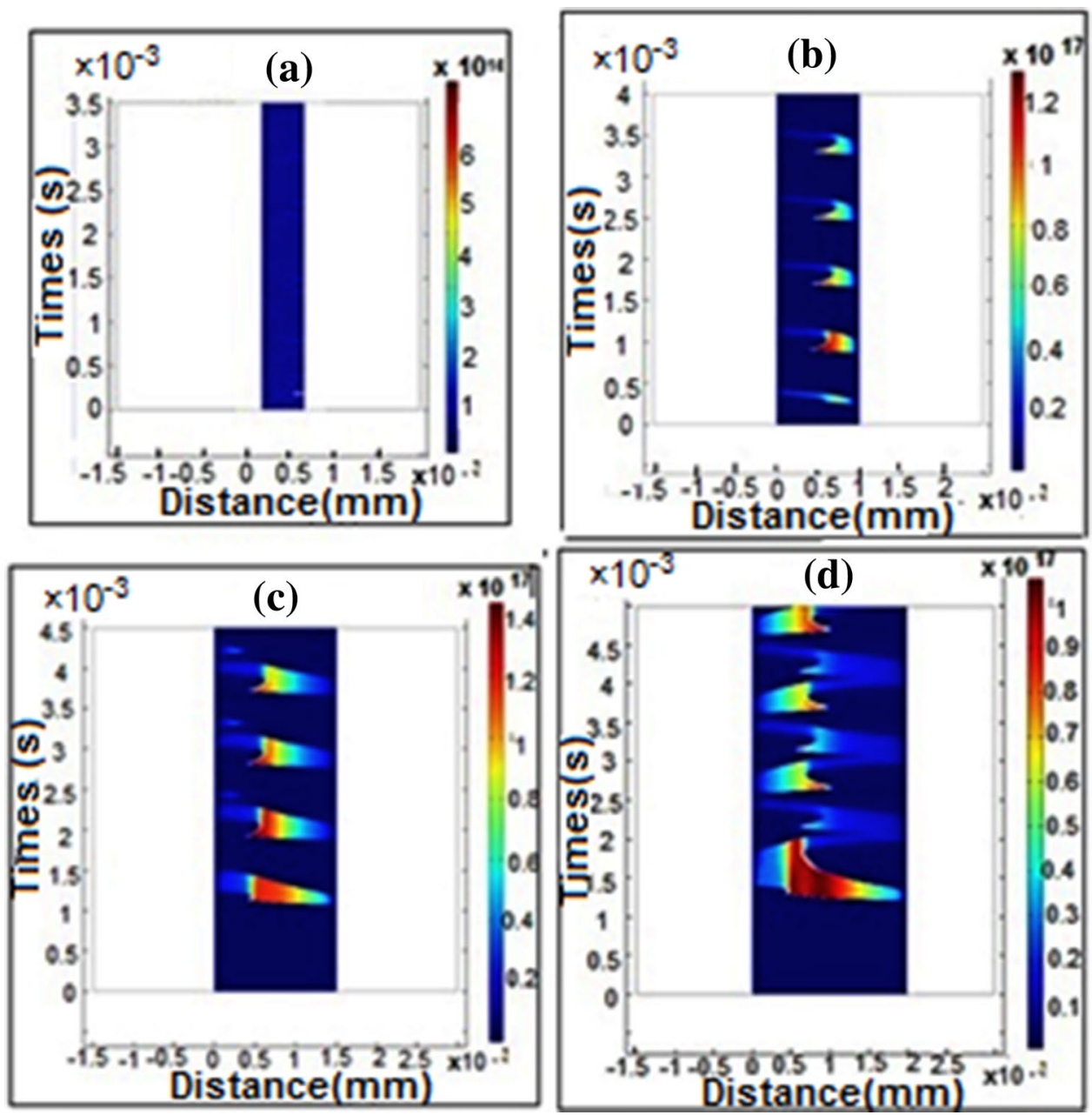

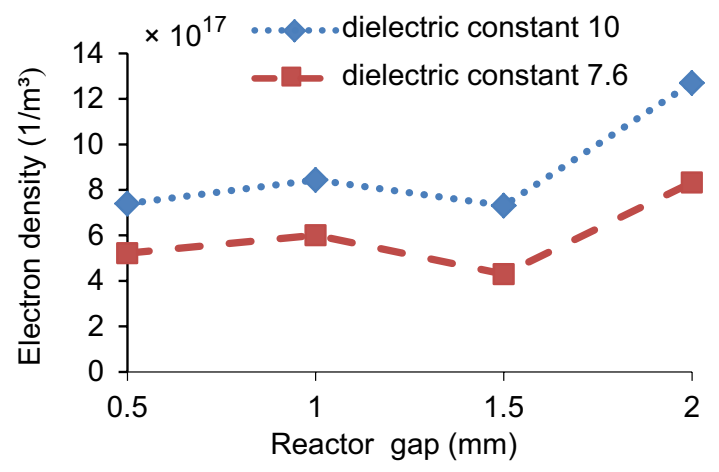

Fig. 4 Electron density plots $\left(1 / \mathrm{m}^{3}\right)$ against the reactor gap for different values of dielectric constant: 7.6 and 10 at the last point in time

\section{Calculations of the DBD's average power consumption for determination of the optimal reactor gap without the presence of any material in the gap region}

In the following step, the influence of variations in the dielectric constant of the dielectric layers which cover both of the electrodes on the average power consumption is investigated in different reactor gaps. At this step, the main focus is to determine the gap that delivers the maximal electric power to the discharge, which is advantageous for material processing applications [19]. For further comparability, the average power consumption within the range of $10 \mu$ s to $100 \mu$ s needs to be calculated.

The plots of average power consumption for the DBDs with different values of dielectric constant (7.6 and 10) are displayed, respectively, in Fig. 17a, b, as a function of the discharge time in different reactor gaps $0.5 \mathrm{~mm}, 1 \mathrm{~mm}$, $1.5 \mathrm{~mm}$ and $2 \mathrm{~mm}$. Accordingly, at the gap of 0.5 , varying the dielectric constant from 7.6 to 10 increases the average power consumption from $0.7 \mathrm{w}$ to $1.1 \mathrm{w}$. However, slope of the plots illustrates approximately a linear behavior. Such linear behavior can be due to the stability of the plasma created in the gap of $0.5 \mathrm{~mm}$ for a wide range of discharge time $(10 \mu \mathrm{s}-100 \mu \mathrm{s})$. Furthermore, it can be seen that as the gap is assumed to be $1 \mathrm{~mm}$, both of the DBD reactors with different values of dielectric constant possess the maximum values of average power consumption. Therefore, this distance can be considered as optimal gap. From Fig. 17a, $\mathrm{b}$, it is clearly illustrated that by increasing the dielectric 
Fig. 5 Spatiotemporal evolutions of mass fraction of Ar* versus the gap spacing for DBD with dielectric constant 7.6 when reactor gap is variable: a $0.5 \mathrm{~mm}, \mathbf{b} 1 \mathrm{~mm}, \mathbf{c} 1.5 \mathrm{~mm}$ and d $2 \mathrm{~mm}$
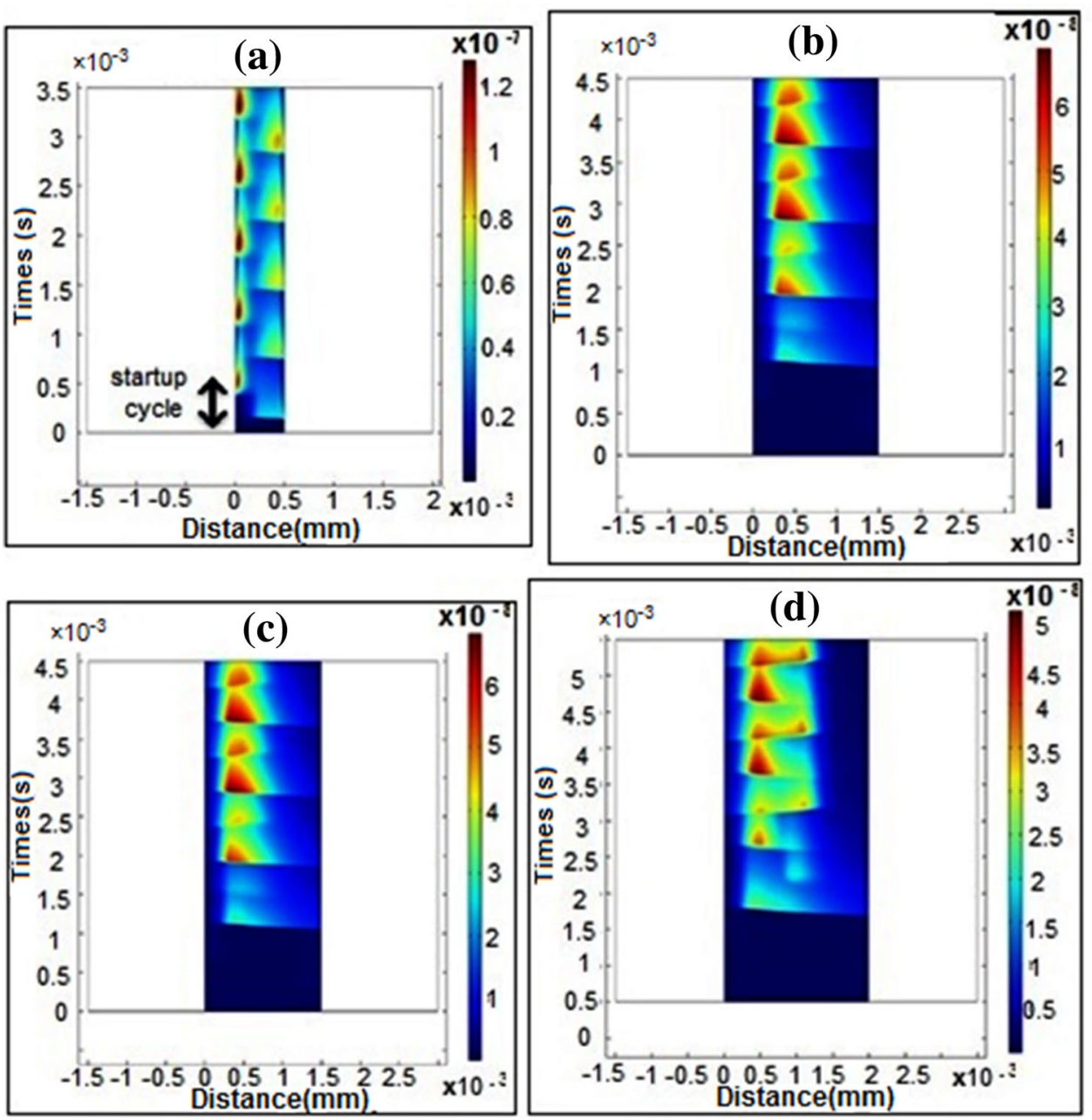

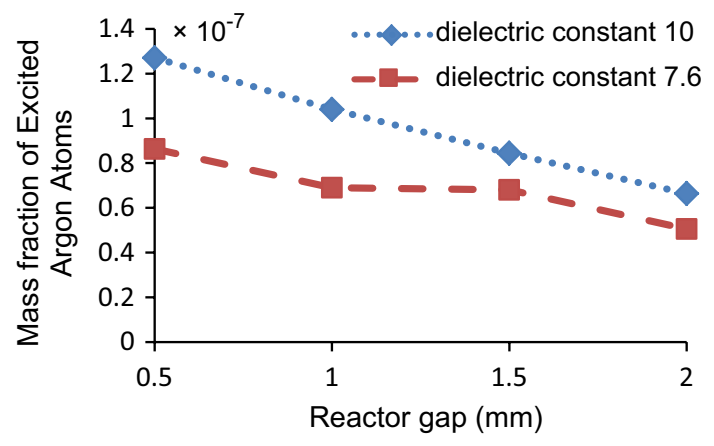

Fig. 6 Mass fraction plots of Ar* against the reactor gap for different values of dielectric constant: 7.6 and 10 at the last point in time

constant of dielectric layers from 7.6 to 10 , the maximum values of average power consumption are obtained in the lower gap distances $(0.5 \mathrm{~mm}$ and $1 \mathrm{~mm})$. For the reactor gaps of $1.5 \mathrm{~mm}$ and $2 \mathrm{~mm}$, we can see the remarkable fluctuations in the plots of average power consumption. It is due to the fact that the produced plasma in the range of discharge time
$0 \mu \mathrm{s}-40 \mu \mathrm{s}$ is still unstable. However, for the minimum reactor gap $(0.5 \mathrm{~mm})$, the produced plasma shows stability in a wide range of discharge time (10 $\mu \mathrm{s}-100 \mu \mathrm{s})$.

\section{Design guidelines for the DBD including materials with different dielectric constant in the discharge gap}

It is a challenging task to investigate numerically the influence of embedding material in the gap distance of a DBD reactor for the surface processing. Thus, in all of the following "Evaluations of the electron densities across the discharge domain," "Evaluations of the mass fraction of excited argon atoms ( $\left.\mathrm{Ar}^{*}\right)$ created in the discharge domain," "Evaluations of the electron temperature and the mean electron energy in the discharge domain" and "Evaluations of the total plasma current density in the discharge domain" sections, three materials with various values of the dielectric constant: aluminum, glass (quartz) and silicon, are embedded in the gap region (between the two electrodes which 
Fig. 7 Spatiotemporal electron temperature evolutions in discharge gap for the DBD with dielectric constant 7.6 and the gap distances of: a $0.5 \mathrm{~mm}$ and b $2 \mathrm{~mm}$

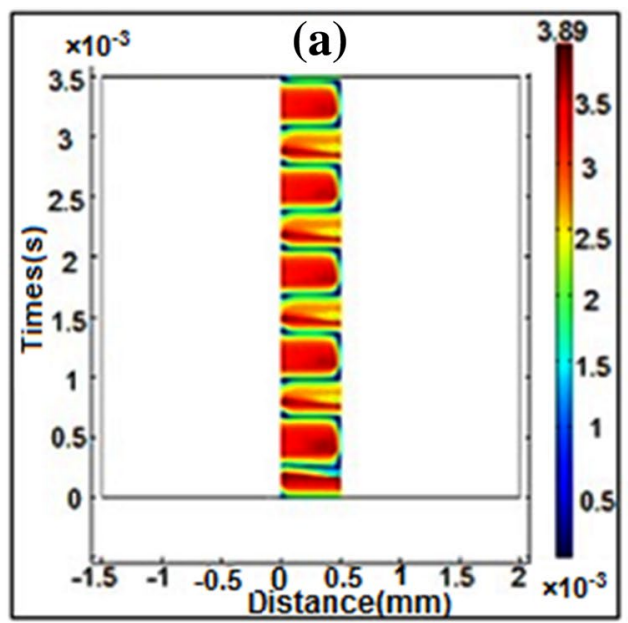

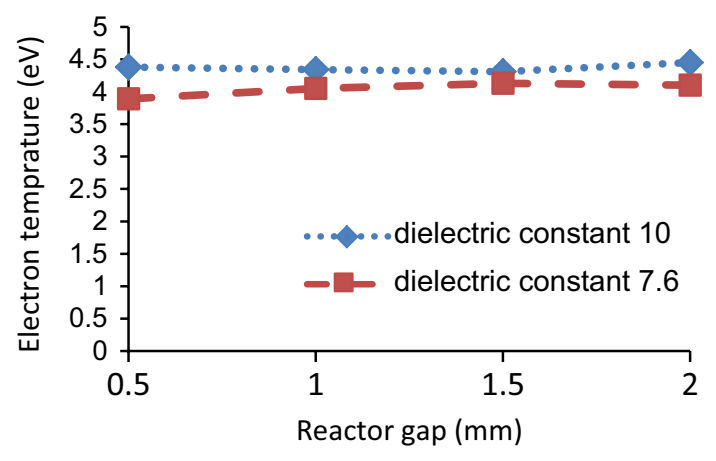

Fig. 8 Electron temperature plots against the reactor gap for different values of dielectric constant: 7.6 and 10 at the last point in time

are covered by dielectric layers with dielectric constant 10), respectively.

To analyze the effect of variation in the relative permittivity of the treated material, thicknesses of the examined materials are assumed to be constant and are equal to $0.2 \mathrm{~mm}$ in all of the following sections. The values of dielectric constants of these treated materials are given in Table 6 .

Moreover, values of the applied voltage, diameter of the electrodes and thickness of the dielectric layers which cover both of the electrodes are assumed to be constant and are given in Table 1. However, in this section, the value of frequency is considered to be $30 \mathrm{kHz}$. The onedimensional (1D) discharge geometry of the proposed DBD with material in the gap region is shown in Fig. 18a, and its 3D structure is also demonstrated in Fig. 18b.

\section{Evaluations of the electron density, ion density and total plasma current densities $\left(J_{p}\right)$ for the DBD with material in the discharge domain}

To investigate the effect of different materials in the gap distance on the electrical discharge properties, the $V-I$ characteristics of the discharge across the gap in different distances $(0.5 \mathrm{~mm}$ and $2 \mathrm{~mm})$ are shown in Figs. 19, 20 and 21 , respectively, at frequency of $30 \mathrm{kHz}$. Accordingly, the
Fig. 9 Spatiotemporal mean electron energy evolutions in discharge gap for the DBD with dielectric constant 7.6 and the gap distances of: a $0.5 \mathrm{~mm}$ and b $2 \mathrm{~mm}$
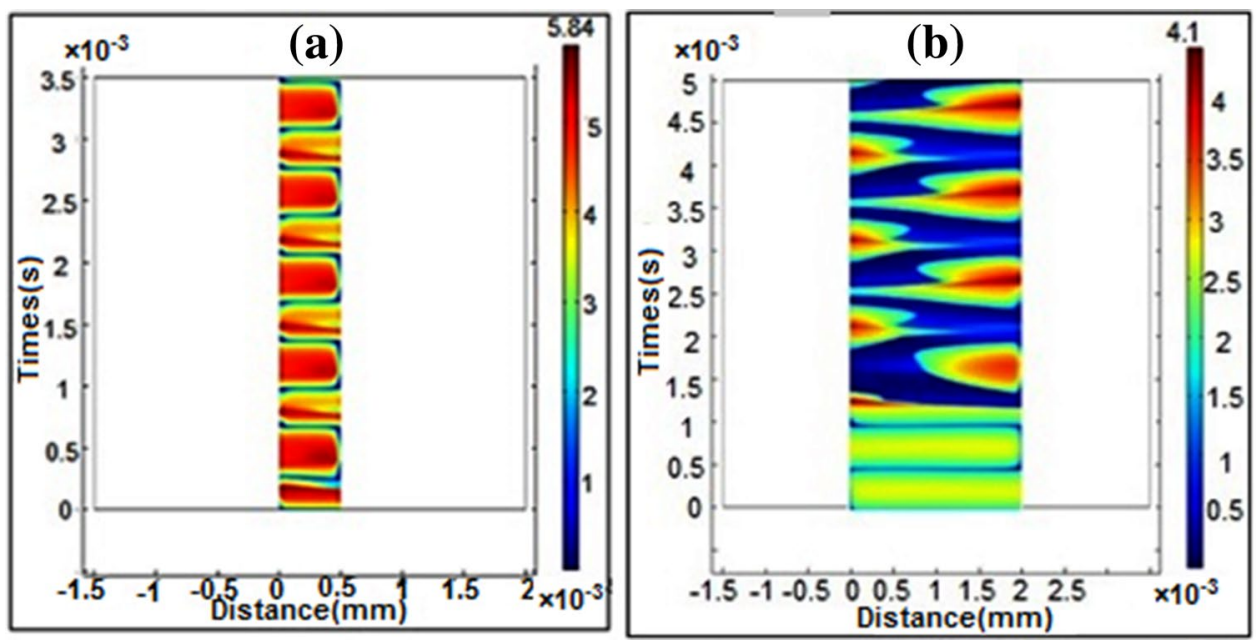


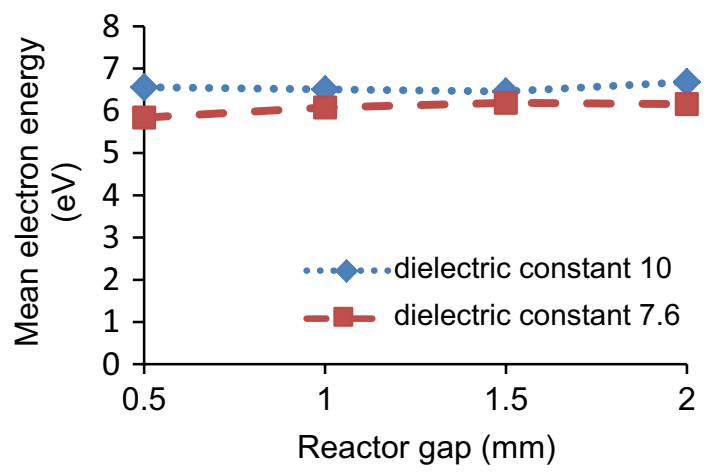

Fig. 10 Mean electron energy against the reactor gap for different values of dielectric constant: 7.6 and 10 at the last point in time

maximum of discharge current at gap $0.5 \mathrm{~mm}$ is $15.647 \mathrm{~mA}$, $19.328 \mathrm{~mA}$ and $20.285 \mathrm{~mA}$ for aluminum, glass and silicon, respectively. Also, at the highest gap distance $2 \mathrm{~mm}$, the maximum of discharge current is still decreased to
$5.422 \mathrm{~mA}, 5.832 \mathrm{~mA}$ and $5.913 \mathrm{~mA}$ for aluminum, glass and silicon, respectively. Therefore, compared to Fig. 2, it can be seen that the maximum of discharge current is remarkably decreased with embedding materials across the gap, due to recombination of charged particles on the material surfaces. Figures 22, 23 and 24 illustrate the evolutions for the electron density, ion density and total plasma current density across the gap of the DBD with dielectric constant 10 as the three materials with different values of relative permittivity (aluminum, glass and silicon) are embedded in the reactor gap $2 \mathrm{~mm}$, respectively. It can be seen in Fig. 22 that the discharge occurs twice in each cycle: one in the positive and the other in the negative half cycle of the voltage. Figure 25a shows that the electron density increases considerably as a function of reactor gap, when the treated material in the gap is silicon with the highest value of dielectric constant compared to the other examined materials, especially aluminum. Indeed, as the reactor gap is varied from $0.5 \mathrm{~mm}$ to $2 \mathrm{~mm}$, the electron density illustrates approximately
Fig. 11 Spatiotemporal electron current density evolutions in dielectric constant 7.6 and the gap distances of: a $0.5 \mathrm{~mm}$ and b $2 \mathrm{~mm}$ discharge gap for the DBD with
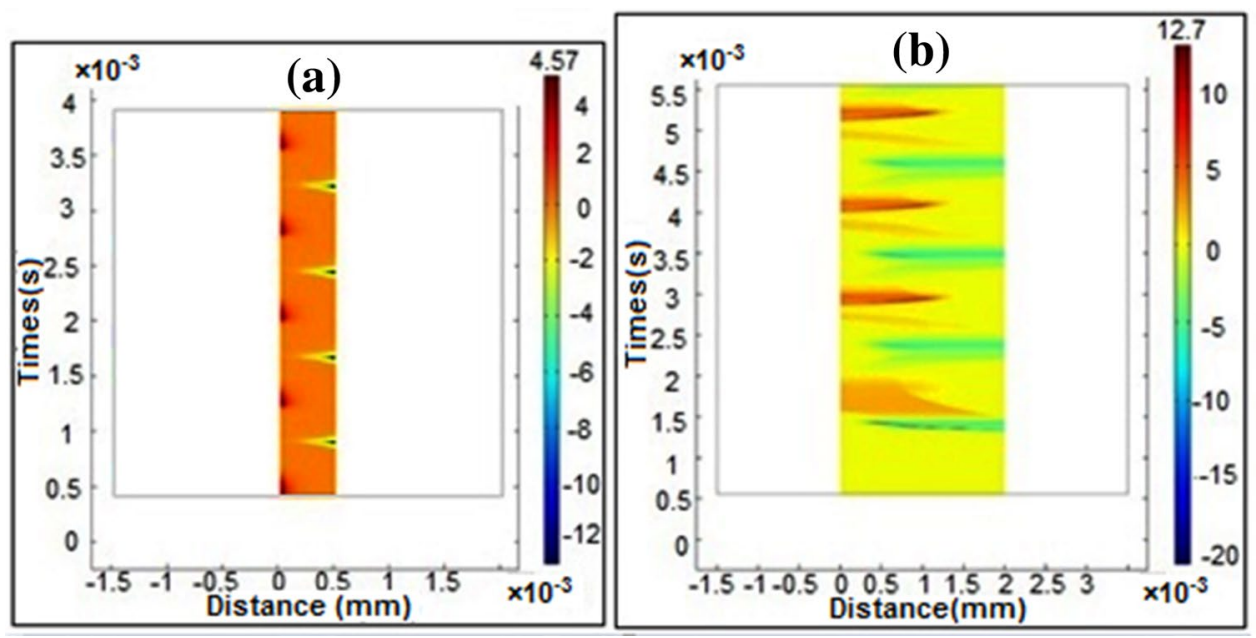

Fig. 12 Spatiotemporal ion current density evolutions in discharge gap for the DBD with dielectric constant 7.6 and the gap distances of: a $0.5 \mathrm{~mm}$ and b $2 \mathrm{~mm}$
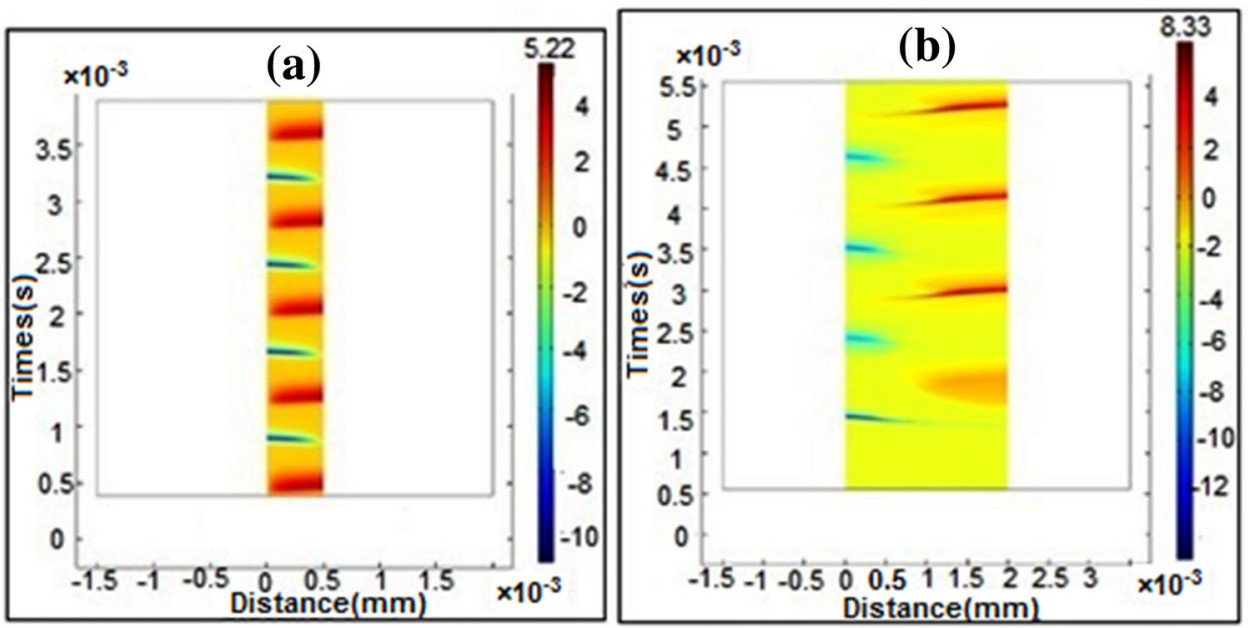
Fig. 13 Spatiotemporal total plasma current density evolutions in discharge gap for the DBD with dielectric constant 7.6 and the gap distances of: a $0.5 \mathrm{~mm}$ and $\mathbf{b} 2 \mathrm{~mm}$

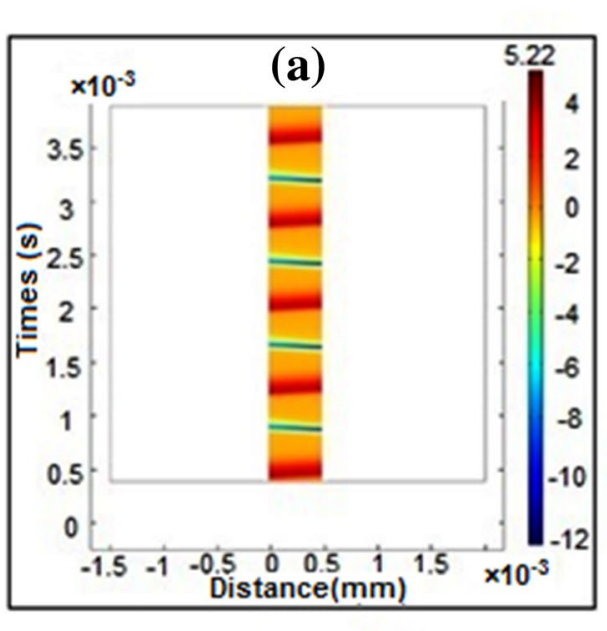

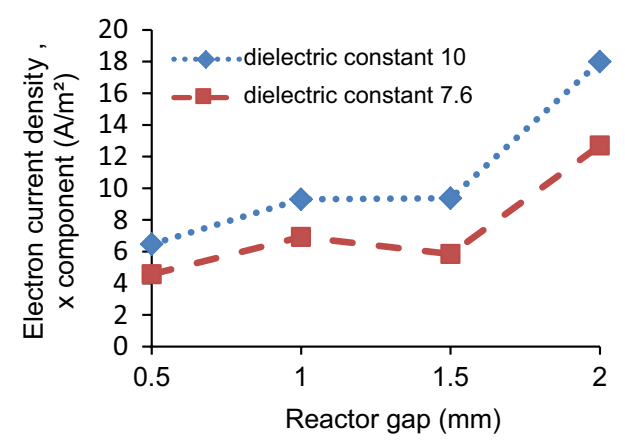

Fig. 14 Electron current density curves against the reactor gap for different values of dielectric constant: 7.6 and 10 at the last point in time

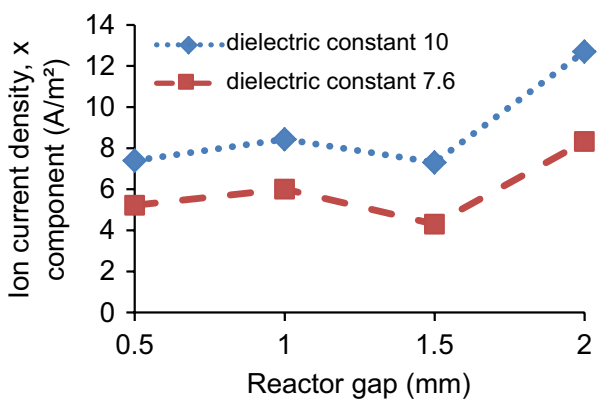

Fig. 15 Ion current density $\left(\mathrm{A} / \mathrm{m}^{2}\right)$ curves against the reactor gap for different values of dielectric constant: 7.6 and 10 at the last point in time

an increasing linear behavior for aluminum. However, as the treated material is replaced with glass (a material with higher value of dielectric constant than aluminum), slope of the corresponding plot increases drastically. Also, in this section, with increasing the gap distance, we can see that the maximum of electron density is increased about $10^{8}$ times lower than for the DBD without any material across the gap

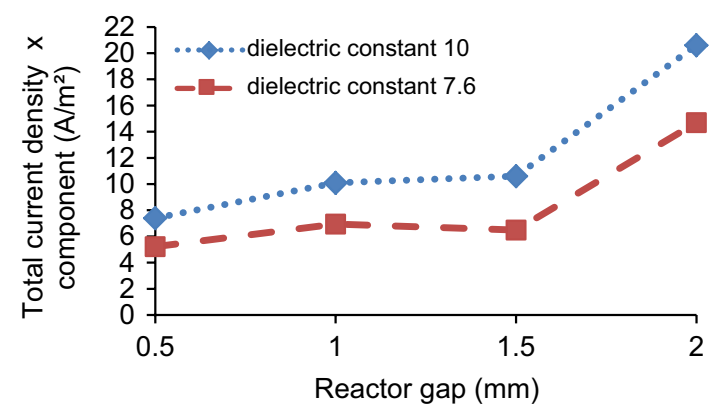

Fig. 16 Total plasma current density $\left(\mathrm{A} / \mathrm{m}^{2}\right)$ against the reactor gap for different values of dielectric constant: 7.6 and 10 at the last point in time

due to recombination of charged particles on the material surfaces.

From Fig. 25a, b, it is easily notified that with increasing gap distances, both of the argon ion density and electron density plots show the same behavior. Moreover, it is shown in Fig. 25b that embedding material with higher dielectric constant than the dielectric layers which cover both of the DBD electrodes (the presence of silicon across the discharge gap) leads to the increment in argon ion density remarkably.

Compared to Fig. 13, it is easily notified that the presence of examined materials in the gap region decreases considerably the values of total plasma current density (see Fig. 25c: for example, at the gap of $1 \mathrm{~mm}$, the DBD without any material across discharge gap offers $J_{\mathrm{p}}=10.1 \mathrm{~A} /$ $\mathrm{m}^{2}$; however, the DBD with silicon in the gap possesses $J_{\mathrm{p}}=0.858 \mathrm{~mA} / \mathrm{m}^{2}$ ). Also, the total plasma current density increases linearly for aluminum as the gap is varied to $2 \mathrm{~mm}$. However, it should be noted that by varying the material across the gap from aluminum to glass or silicon, the maximum of both electron and argon ion densities is obtained at the reactor gap of $1.5 \mathrm{~mm}$. On the other hand, 

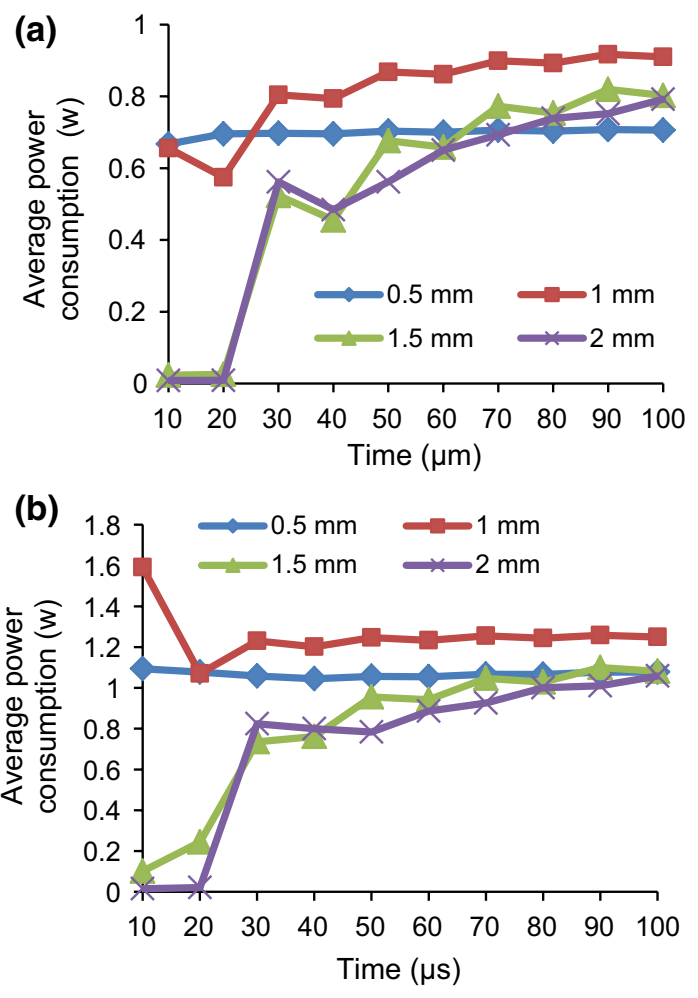

Fig. 17 Plots of the average power consumption against the discharge times $(10 \mu \mathrm{s}-100 \mu \mathrm{s})$ for the DBDs with dielectric constant a 7.6 and b 10

Table 6 Properties of examined materials

\begin{tabular}{lcll}
\hline Treated materials & $\begin{array}{l}\text { Dielectric } \\
\text { constant }\end{array}$ & Unit & Refractive index \\
\hline Aluminum & 1 & 1 & - \\
Glass (quartz) & 4.2 & 1 & 1.45 \\
Silicon & 11.7 & 1 & 1.5 \\
\hline
\end{tabular}

the maximum of total plasma current density $(0.858 \mathrm{~mA} /$ $\mathrm{m}^{2}$ ) is obtained in the gap of $1 \mathrm{~mm}$ for silicon. Furthermore, the remarkable variations in the total plasma current density are obtained for silicon with higher dielectric constant than the dielectric constant of aluminum, glass and also dielectric layers. Consequently, it should be highlighted that the variations in the electron, argon ion and total plasma current densities as a function of reactor gap depend noticeably on the nature of the treated material.

\section{Evaluations of number density and mass fraction of the excited argon atoms (Ar*) for the DBD with material in the discharge domain}

Figure 26 depicts the evolutions for mass fraction of the excited argon atoms across the gap of the DBD with dielectric constant 10 as the three materials with different values of relative permittivity (aluminum, glass and silicon) are embedded in the reactor gap $2 \mathrm{~mm}$, respectively.

According to Fig. 27a, b, the variation in the mass fraction and density of the excited argon atoms across the reactor gap illustrates nearly the same behavior for all of the treated materials. Also, the presence of aluminum (the examined material with the lowest dielectric constant) cannot change not only mass fraction but also density of the excited argon atoms remarkably, as the gap is increased. However, similar to the plots of electron density and argon ion density (see Fig. 25a, b), the maximum values of the mass fraction and density of Ar* are achieved for silicon

Furthermore, Fig. 27a shows that the DBD with different materials across the discharge gap (particularly aluminum) decreases the mass fraction of Ar* compared to the DBD without any materials between the two dielectric layers.

\section{Evaluations of the electron temperature for the DBD with different materials in the discharge domain}

According to Fig. 28, as the reactor gap is increased from $0.5 \mathrm{~mm}$ up to $2 \mathrm{~mm}$, the electron temperature plots decrease exponentially (with a slow slope) for all of the treated materials. Therefore, the variation in the nature of the examined material cannot affect the electron temperature considerably.

\section{Calculations of the DBD's power consumption for determination of the optimal reactor gap of the DBD with different materials in the gap region}

Figure 29 depicts the variation in the average power consumption within the range of $10 \mu$ s to $100 \mu$ s, for the DBD without any material in the discharge gap $0.5 \mathrm{~mm}$ at frequency of $30 \mathrm{kHz}$. From this figure, it is clearly shown that the average power consumption reaches its minimum value in the half cycle of the discharge time.

In Fig. 30a-c, the plots of average power consumption for the reactor gap distances of $0.5 \mathrm{~mm}, 1 \mathrm{~mm}, 1.5 \mathrm{~mm}$ and $2 \mathrm{~mm}$, respectively, are illustrated to analyze the effects of variation in the nature of the treated materials on the average power absorbed by the plasma. According to Fig. 30a, b, by increasing the gap up to $1 \mathrm{~mm}$, the average power consumptions for the three examined materials increase nearly 10 times greater than the results obtained at the gap of $0.5 \mathrm{~mm}$. Moreover, from Fig. 30a-c, it can be seen that the maximum value of average power consumption is achieved for silicon with the maximum relative permittivity. Also, the variations in the average power consumption within the range of $10 \mu \mathrm{s}$ to $100 \mu \mathrm{s}$, for the three treated materials, illustrate a sinusoidal behavior as the reactor gap is chosen to be $0.5 \mathrm{~mm}$, $1 \mathrm{~mm}$ and $1.5 \mathrm{~mm}$, respectively. As a result, the proposed DBD reactor offers much greater values of average power 
Fig. 18 a The $1 \mathrm{D}$ discharge geometry of the simulated DBD with material in the discharge gap. b The 3D structure of the designed DBD system for material treatment

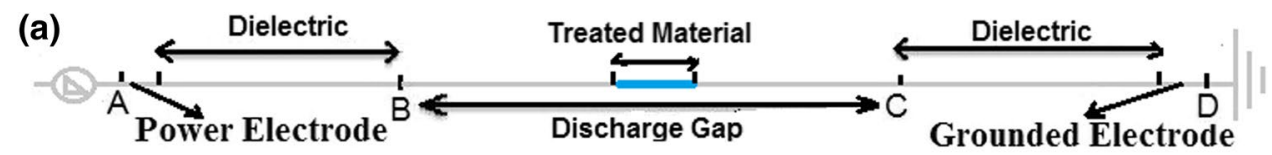

(b)

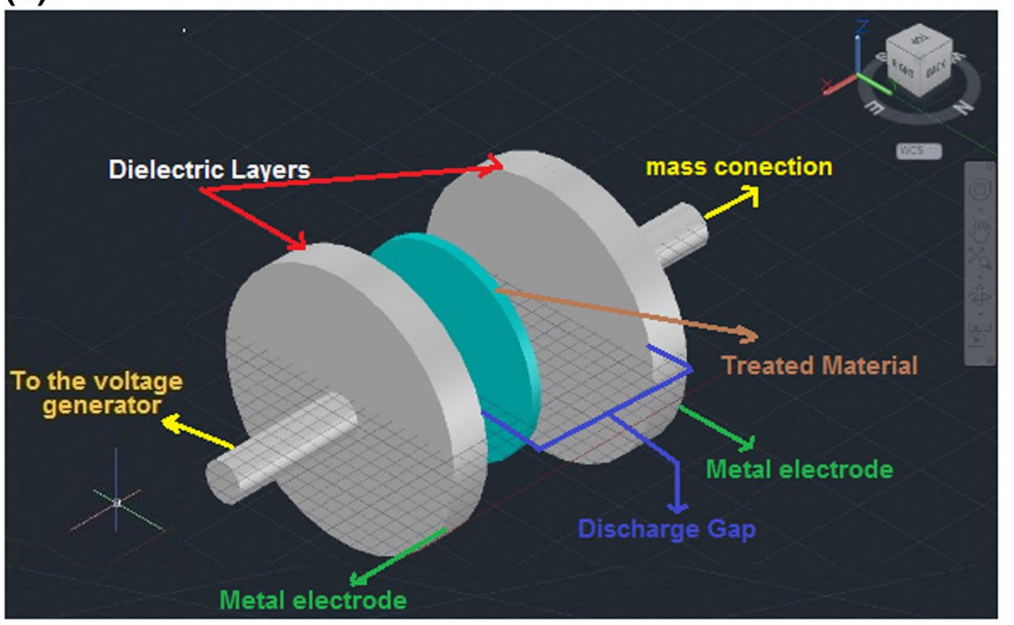

(a)

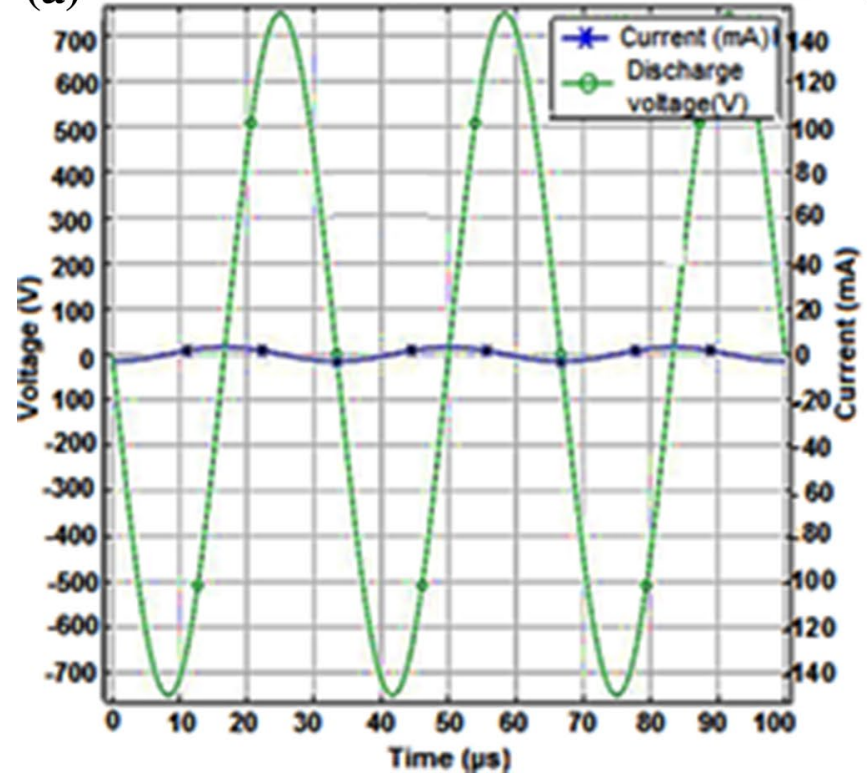

(b)

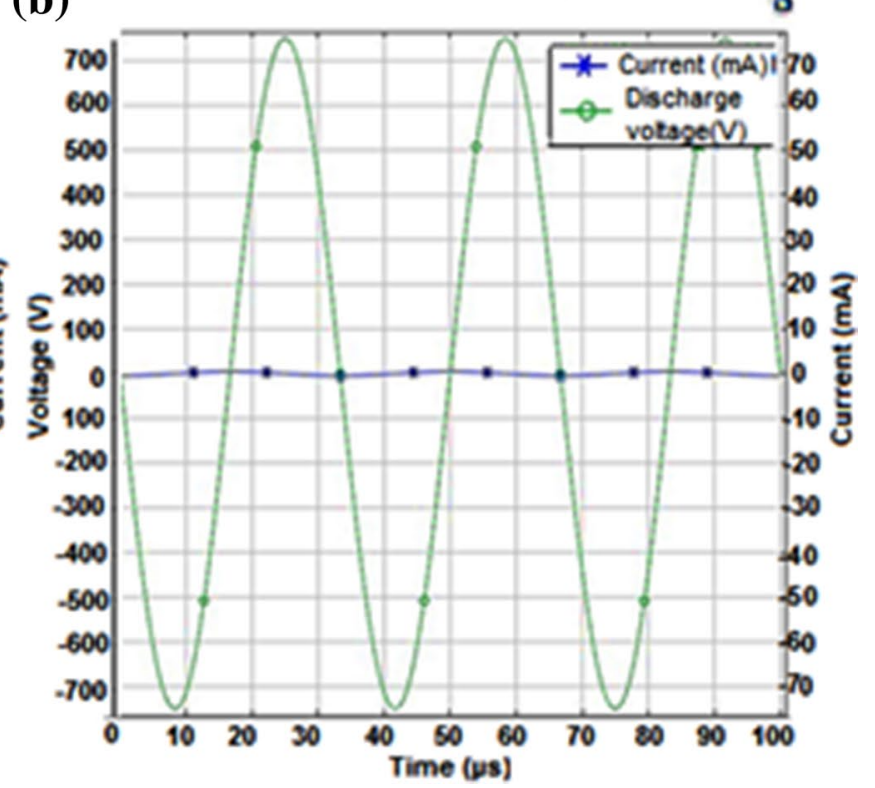

Fig. 19 Current-voltage waveform for discharge with the applied voltage amplitude $750 \mathrm{~V}$ and frequency $30 \mathrm{kHz}$ of the DBD with dielectric constant 10 when aluminum is across different gap distances $\mathbf{a} 0.5 \mathrm{~mm}, \mathbf{b} 2 \mathrm{~mm}$

consumption for not only aluminum but also silicon at the gap $1.5 \mathrm{~mm}$ compared to the other gap distances. For glass, the average of power consumption at the gap distance of $1 \mathrm{~mm}$ is increased nearly 10 times greater than the gap of $0.5 \mathrm{~mm}$. However, the average power consumption cannot change remarkably when the gap distance is increased to $1.5 \mathrm{~mm}$. Consequently, the power absorbed by plasma in the discharge gap (the average power consumption) depends on the nature of the different materials across the gap region for the material treatment.

\section{Conclusion}

In this study, using COMSOL Multiphysics v5.0 software, the characteristics of an argon DBD system at atmospheric pressure under two conditions are investigated. Firstly, the 

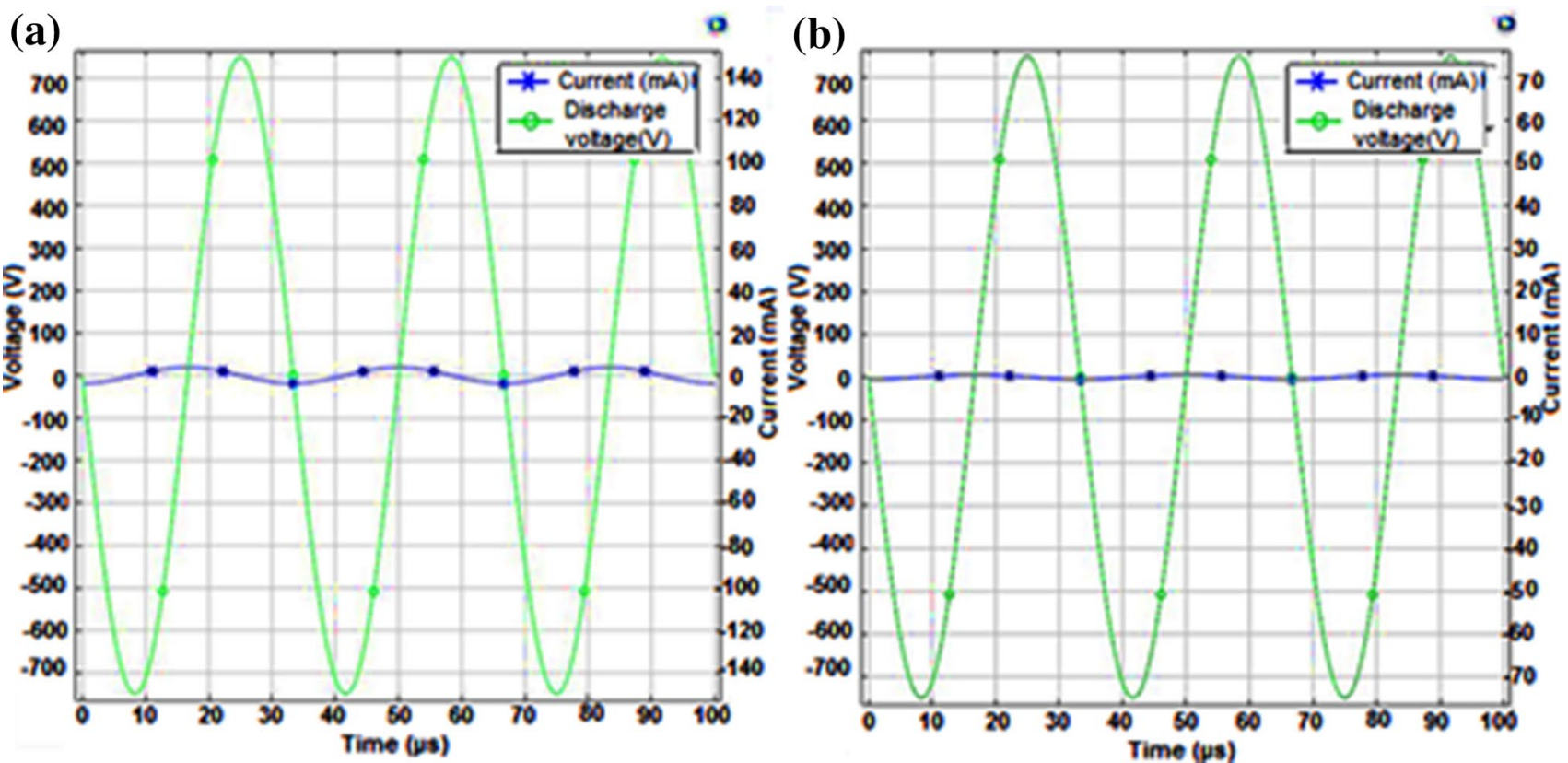

Fig. 20 Current-voltage waveform for discharge with the applied voltage amplitude $750 \mathrm{~V}$ and frequency $30 \mathrm{kHz}$ of the DBD with dielectric constant 10 when glass (quartz) is across different gap distances a $0.5 \mathrm{~mm}, \mathbf{b} 2 \mathrm{~mm}$

(a)

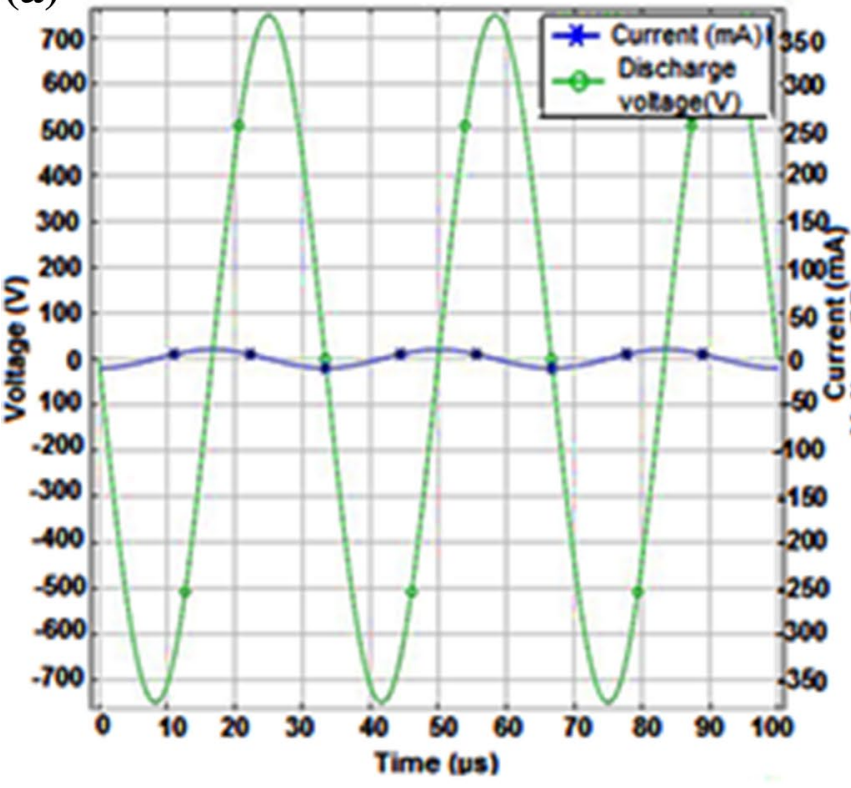

(b)

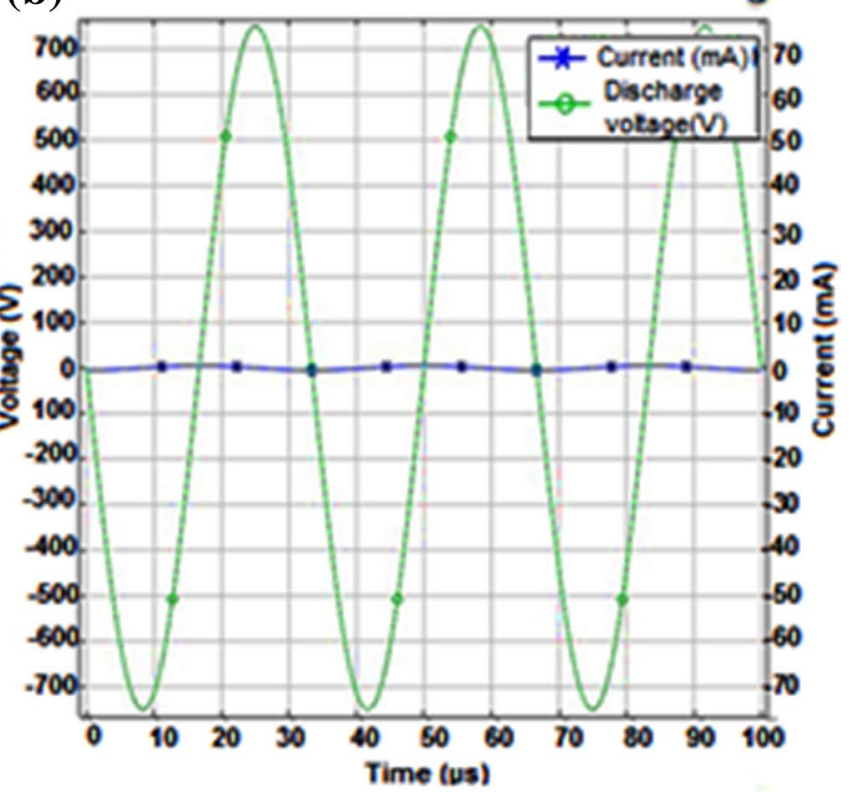

Fig. 21 Current-voltage waveform for discharge with the applied voltage amplitude $750 \mathrm{~V}$ and frequency $30 \mathrm{kHz}$ of the DBD with dielectric constant 10 when silicon is across different gap distances a $0.5 \mathrm{~mm}, \mathbf{b} 2 \mathrm{~mm}$

influence of variations in the reactor gap and the nature of the dielectric layers which cover the metallic electrodes on the electrical characteristics of the DBD reactor are studied. As a conclusion, when the reactor gap exceeds $1 \mathrm{~mm}$, a reduction or disturbance in the electron density in the discharge region can be seen due to the instability of the plasma. The values of mass fraction of Ar* across the discharge region diminish as the gap is varied from $0.5 \mathrm{~mm}$ to $2 \mathrm{~mm}$. Additionally, the electron temperature depends on the nature of the dielectric layers which cover the electrodes compared to reactor gap distance. Moreover, it is obtained that the electron temperature and the 

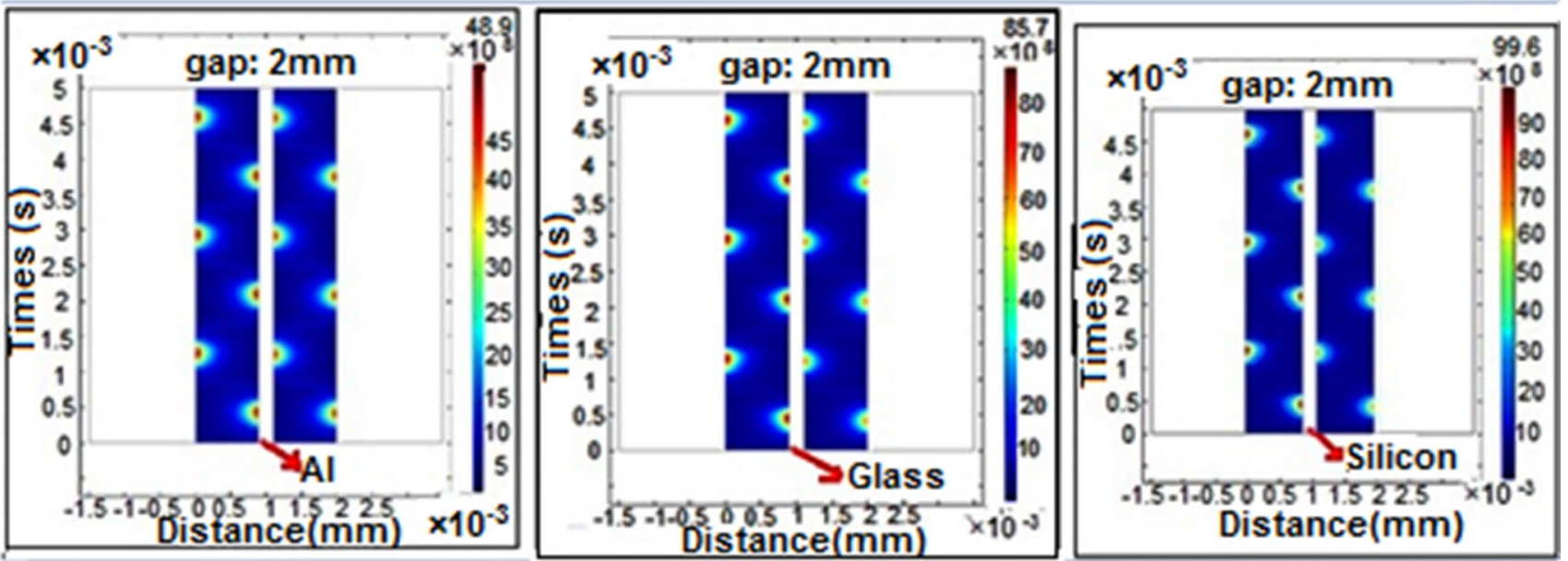

Fig. 22 Spatiotemporal evolutions of the electron density $\left(1 / \mathrm{m}^{3}\right)$ versus the gap spacing for DBD with dielectric constant 10 for different materials across the reactor gap $2 \mathrm{~mm}$
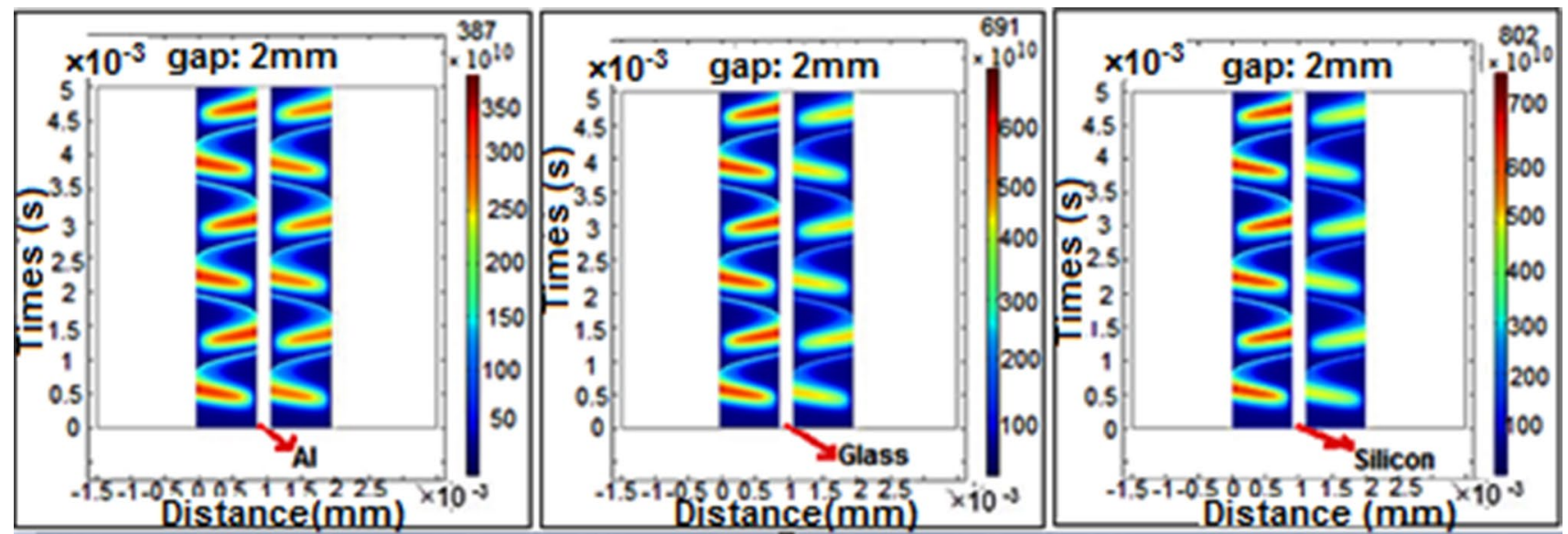

Fig. 23 Spatiotemporal evolutions of argon ion density $\left(1 / \mathrm{m}^{3}\right)$ versus the gap spacing for DBD with dielectric constant 10 for different materials across the reactor gap $2 \mathrm{~mm}$
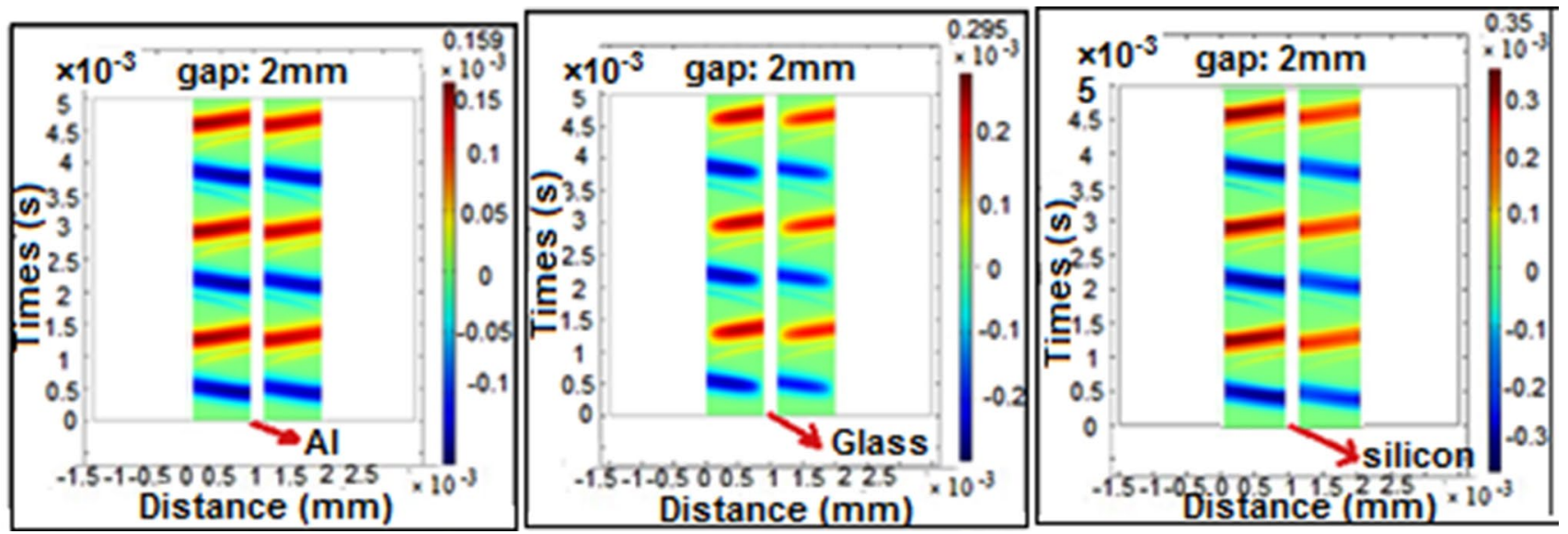

Fig. 24 Spatiotemporal evolutions of total plasma current density $\left(\mathrm{A} / \mathrm{m}^{2}\right)$ versus the gap spacing for DBD with dielectric constant 10 for different materials across the reactor gap $2 \mathrm{~mm}$ 
Fig. 25 Plots of a electron density $\left(1 / \mathrm{m}^{3}\right)$, b argon ion density $\left(1 / \mathrm{m}^{3}\right)$ and $\mathbf{c}$ total plasma current density $\left(\mathrm{mA} / \mathrm{m}^{2}\right)$ against the reactor gap of the DBD considered with dielectric constant 10 for the three treated materials at the last point in time
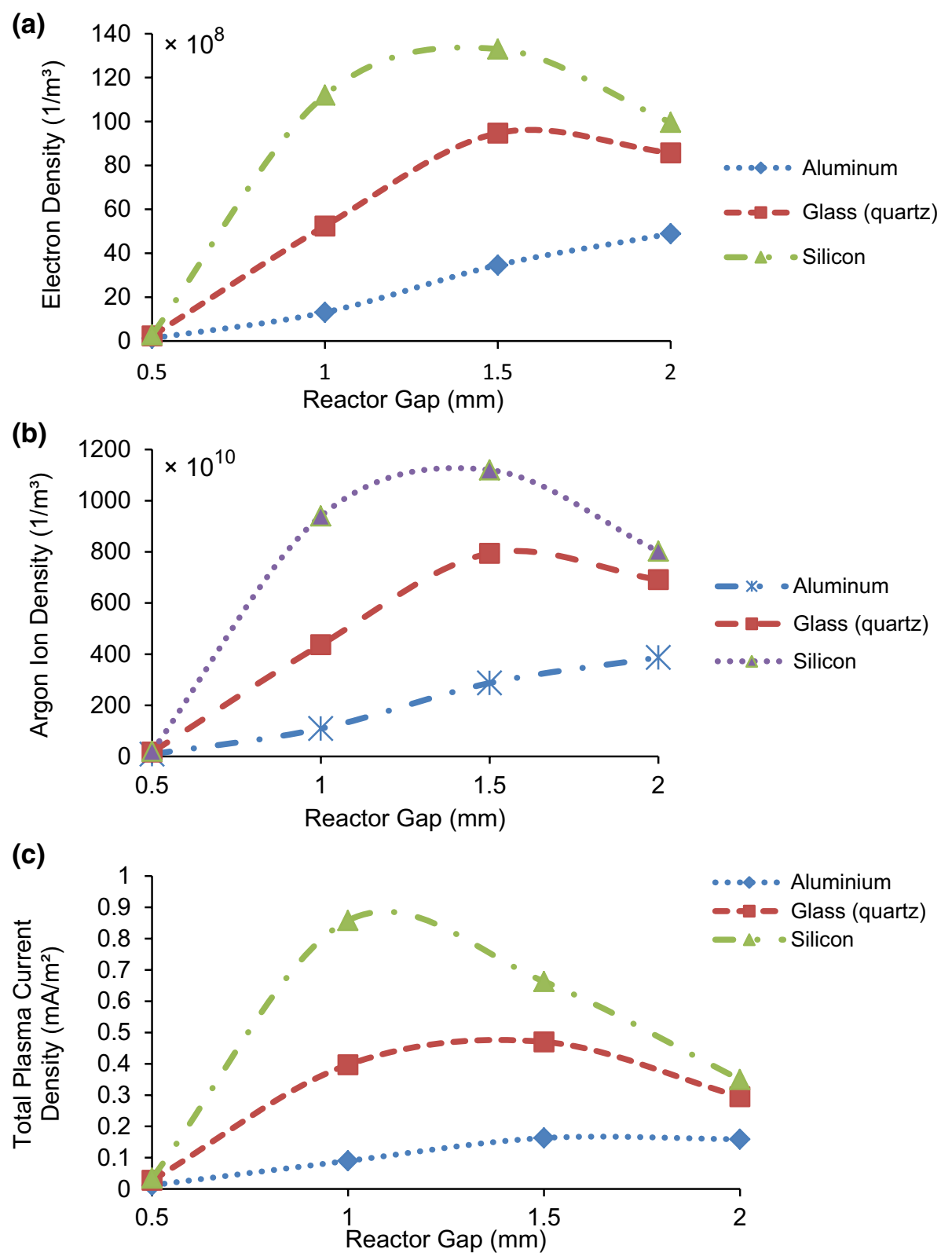

mean electron energy plots against the reactor gap illustrate the same behavior for the two DBDs with various dielectric constants (7.6 and 10). The evaluations of the power consumption plots present that the variation in the nature of the dielectric material of the two electrodes cannot influence significantly the optimal reactor gap $(1 \mathrm{~mm})$. The DBD with dielectric constant 10 offers the maximum power consumption, particularly in the gap distances of
$0.5 \mathrm{~mm}$ and $1 \mathrm{~mm}$ compared to the DBD with dielectric constant 7.6. Furthermore, variation in the nature of the dielectric material which covers both of the electrodes cannot influence significantly the behavior of the power consumption plots versus the discharge time (10-100 $\mu \mathrm{s})$ in all of the examined gaps. To optimize the proposed system for the material treatment, secondly, the influence of embedding different materials with various dielectric 

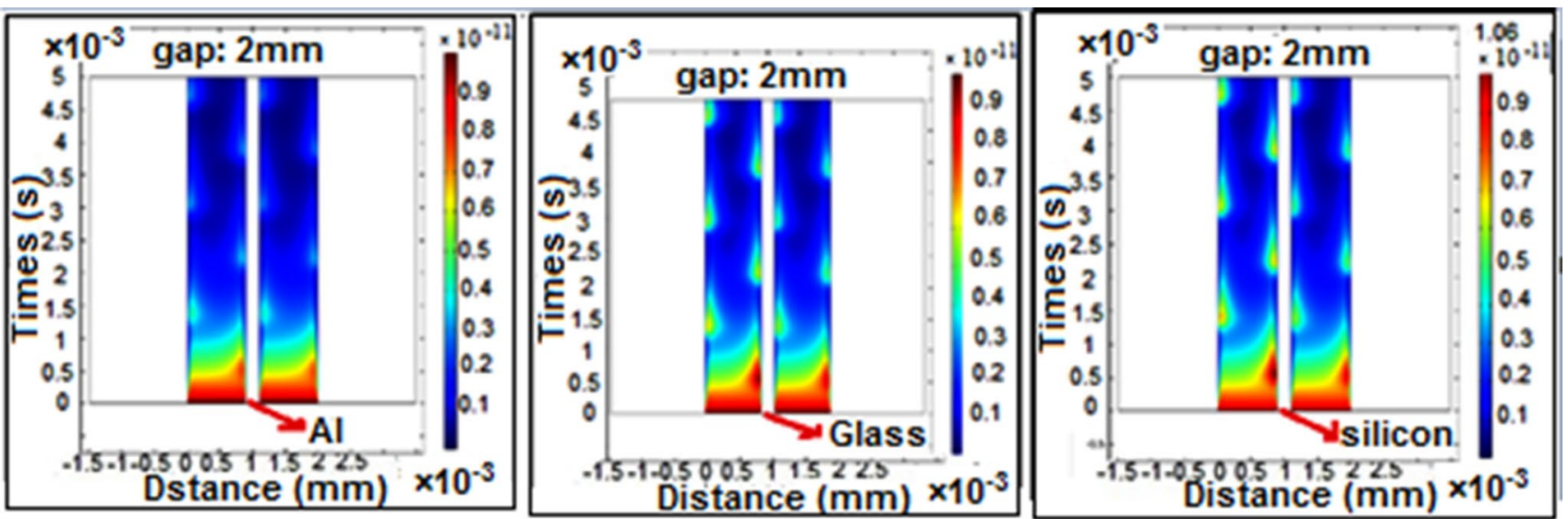

Fig. 26 Spatiotemporal evolutions of mass fraction of the excited argon atoms versus the gap spacing for DBD with dielectric constant 10 for different materials across the reactor gap $2 \mathrm{~mm}$
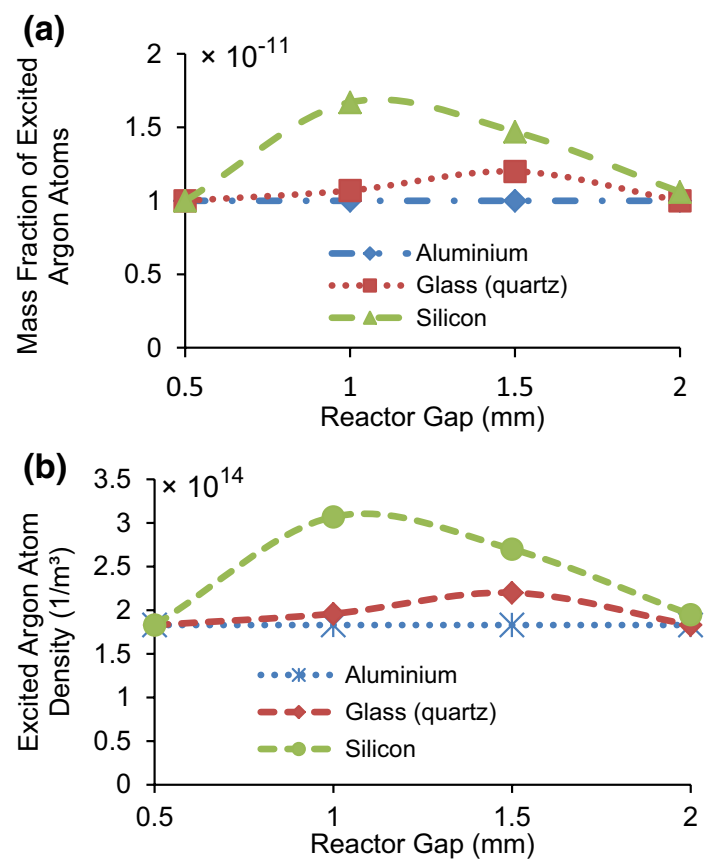

Fig. 27 Plots of $\mathbf{a}$ mass fraction and $\mathbf{b}$ density of the excited argon atoms $\left(1 / \mathrm{m}^{3}\right)$ against the reactor gap of the DBD with dielectric constant 10 for the three treated materials at the last point in time

constants (aluminum, glass and silicon) on the characteristics of the proposed DBD is analyzed. It is concluded that embedding the material with higher value of dielectric

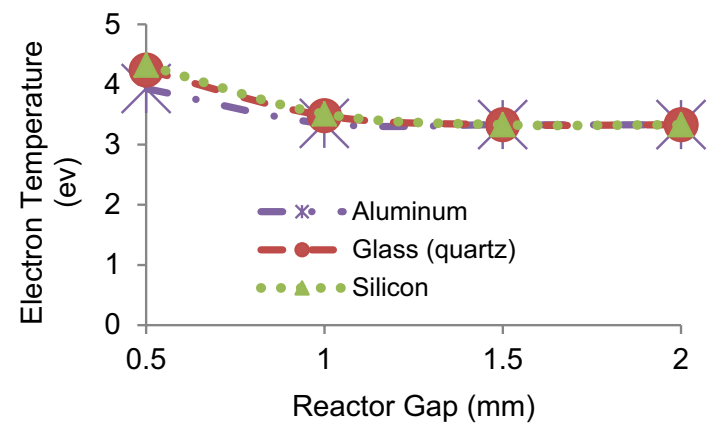

Fig. 28 Plots of electron temperature $(\mathrm{eV})$ against the reactor gap of the DBD with dielectric constant 10 for the three treated materials at the last point in time

constant (silicon: 11.7) across the discharge gap enhances the electron, argon ion and total plasma current densities remarkably compared to aluminum and glass as the reactor gap is varied from $0.5 \mathrm{~mm}$ to $2 \mathrm{~mm}$. Moreover, the variations in the electron, argon ion and total plasma current densities as a function of reactor gap depend on the nature of the treated material noticeably. However, the variation in the nature of the examined material cannot affect the electron temperature considerably. The presence of aluminum does not change remarkably not only mass fraction but also density of the excited argon atoms, as the gap is increased. However, the maximum values of both mass 
Fig. 29 Plots of the average power consumption against the discharge times $(10 \mu \mathrm{s}-100 \mu \mathrm{s})$ related to the DBDs with dielec$0.5 \mathrm{~mm}$ at frequency of $30 \mathrm{kHz}$ tric constant 10 without any materials at the reactor gap of
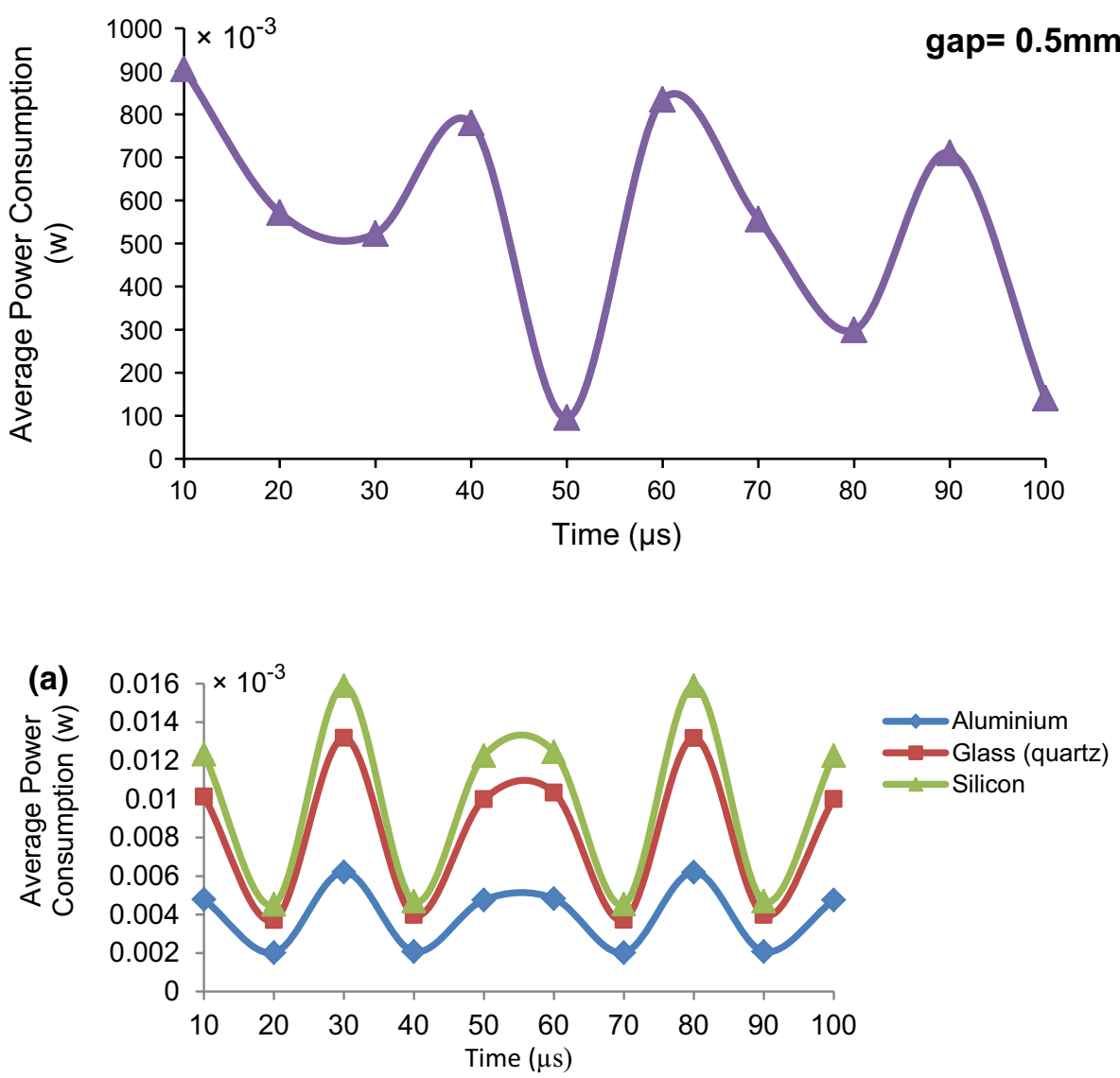

Fig. 30 Plots of the average power consumption against the discharge times $(10 \mu \mathrm{s}-100 \mu \mathrm{s})$ for the DBD with dielectric constant 10 for the three treated materials at the gap distances of a $0.5 \mathrm{~mm}$, b $1 \mathrm{~mm}, \mathbf{c} 1.5 \mathrm{~mm}$
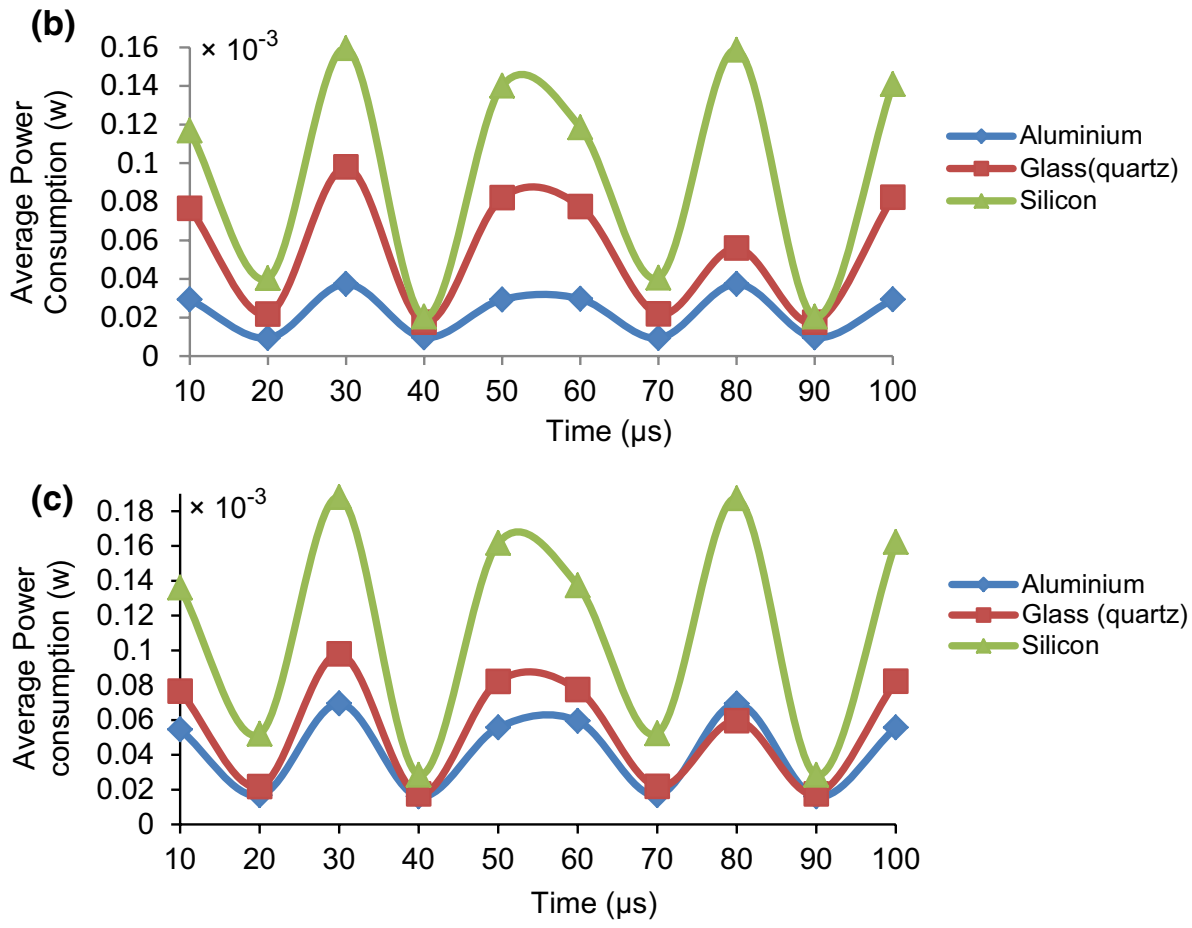
fraction and density of Ar* are obtained for silicon. Furthermore, the presence of the three examined materials at the gap of $0.5 \mathrm{~mm}$ leads to the remarkable reduction in the average power consumption compared to the DBD without any material across the discharge gap.

Acknowledgements The authors would like to offer sincere thanks to Dr. S. M. Sangdehi, Associate Professor, in the Laser and plasma Research Institute, Shahid Beheshti University (SBU), Evin, Iran, for her valuable support in our research work.

Open Access This article is distributed under the terms of the Creative Commons Attribution 4.0 International License (http://creativeco mmons.org/licenses/by/4.0/), which permits unrestricted use, distribution, and reproduction in any medium, provided you give appropriate credit to the original author(s) and the source, provide a link to the Creative Commons license, and indicate if changes were made.

\section{References}

1. Jidenko, N., Jimenez, C., Massines, F., Borra, J.-P.: Nano-particle size-dependent charging and electro-deposition in dielectric barrier discharges at atmospheric pressure for thin $\mathrm{SiO}_{\mathrm{x}}$ film deposition. J. Phys. D Appl. Phys 40, 4155 (2007)

2. Kostov, K.G., Hamia, Y.A.A., Mota, R.P., dos Santos, A.L.R., Nascente, P.A.P.: Treatment of polycarbonate by dielectric barrier discharge (DBD) at atmospheric pressure. J. Phys. Conf. Ser. 511, 012075 (2014). https://doi.org/10.1088/1742-6596/511/1/012075

3. Belmonte, T., Arnoult, G., Henrion, G., Gries, T.: Nanoscience with non-equilibrium plasmas at atmospheric pressure. J. Phys. D 44, 363001 (2011)

4. Kogelschatz, U.: Fundamentals and applications of dielectric barrier discharges. In: HAKONE VII International Symposium on high pressure low temperature plasma chemistry, Greifswald (2000)

5. Hoffman, C., Berganza, C., Zhang, J.: Cold atmospheric plasma: methods of production and application in dentistry and oncology. Med Gas Res (2013). https://doi. org/10.1186/2045-9912-3-21

6. Fanelli, F., Fracassi, F.: Atmospheric pressure non-equilibrium plasma jet technology: general features, specificities and applications in surface processing of materials. Surf Coat Technol (2017). https://doi.org/10.1016/j.surfcoat.2017.05.027

7. Deng, S., Ruan, R., Mok, C.K., Huang, G., Lin, X.: Inactivation of Escherichia coli on almonds using non thermal plasma. J Food Sci (2007). https://doi.org/10.1111/j.1750-3841.2007.00275.x

8. Fridman, G., Gutsol, A., Shekhter, A.B., Vasilets, V.N., Fridman, A.: Applied plasma medicine. Plasma Process Polym (2008). https ://doi.org/10.1002/ppap.200700154

9. Arora, V., Nikhil, V., Suri, N.K., Arora, P.: Cold atmospheric plasma (CAP) in dentistry. Dentistry (2014). https://doi. org/10.4172/2161-1122.1000189

10. Tarasenko, V.F.: Excilamps as efficient UV-VUV light sources. Pure Appl. Chem. 74, 465-469 (2002)

11. Rahul, G.N., Ajit, G.D., Shivraj, B.K., Yingjie, C.: Effect of dielectric barrier discharge parameters on certain properties of natural polymeric material (cotton) fiber. Am. J. Polym. Sci. Eng. 3, 183-197 (2015)
12. Chirokov, A., Gutsol, A., Fridman, A.: Atmospheric pressure plasma of dielectric barrier discharges. Pure Appl. Chem. 77, 487-495 (2005)

13. Bhosle, S., Diez, R., Piquet, H., Thanh, D.L., Rahmani, B., Buso, D.: Modeling of a dielectric barrier discharge lamp for UV production. In: Proceedings of the COMSOL Conference, Hannover (2008)

14. Baroch, P., Saito, N.: Dielectric barrier discharge system with catalytically active porous segment for improvement of water treatment. In: Proceedings of the ISPC-Conference, p. 423 (2008) Retrieved 9 January 2011

15. Kirkpatrick, M., Dodet, B., Odic, E.: Atmospheric pressure humid argon DBD plasma for the application of sterilization measurement and simulation of hydrogen, oxygen, and hydrogen peroxide formation. Int. J. Plasma Environ. Sci. Technol. 1, 96-101 (2007)

16. Oppenlander, T., Sosnin, E.: Mercury free (VUV) and UV excil lamps: lamps of the future. IUVA News 7, 16-20 (2005)

17. Pietsch, G.J.: Peculiarities of dielectric barrier discharges. Contrib. Plasma Phys. 41, 620-628 (2001)

18. Kogelschatz, U.: Dielectric-barrier discharges: their history, discharge physics, and industrial applications. Plasma Chem. Plasma Proc. 23, 1-46 (2003)

19. Kostov, G., Honda, R.Y., Alves, L.M.S., Kayama, M.E.: Characteristics of dielectric barrier discharge reactor for material treatment. Braz. J. Phys. (2009). https://doi.org/10.1590/S0103-97332 009000300015

20. Sohbatzadeh, F., Soltani, H.: Time-dependent one-dimensional simulation of atmospheric dielectric barrier discharge in $\mathrm{N}_{2} / \mathrm{O}_{2} /$ $\mathrm{H}_{2} \mathrm{O}$ using COMSOL multiphysics. J. Theor. Appl. Phys. 12, 53-63 (2018). https://doi.org/10.1007/s40094-018-0281-4

21. Sharma, R., Holcomb, E., Trigwell, S., Mazumder, M.: Stability of atmospheric-pressure plasma induced changes on polycarbonate surfaces. J. Electrost. 65, 269 (2007). https://doi.org/10.1016/j. elstat.2006.10.001

22. Šira, M., Trunek, D., St'ahel, P., Bursikova, V., Navratil, Z.: Surface modification of polycarbonate in homogeneous atmospheric pressure discharge. J. Appl. Phys. D 41, 015207 (2008)

23. Nastuta, A.V., Rusu, G.B., Topala, I., Chiper, A.S., Popa, G.: Surface modifications of polymer induced by atmospheric DBD plasma in different configurations. J. Optoelectron. Adv. Mater. 10, 2038-2042 (2008)

24. Bornholdt, S., Wolter, M., Kersten, H.: Characterization of an atmospheric pressure plasma jet for surface modification and thin film deposition. Eur. Phys. J. D 60, 653-660 (2010)

25. Hofmann, S., Van Gils, K., Van der Linden, S., Iseni, S., Bruggeman, P.: Time and spatial resolved optical and electrical characteristics of continuous and time modulated RF plasmas in contact with conductive and dielectric substrates. Eur. Phys. J. D (2014). https://doi.org/10.1140/epjd/e2014-40430-3

26. Zendehnam, A., Ghasemi, J., Zendehnam, A.: Employing cold atmospheric plasma (Ar, He) on $\mathrm{Ag}$ thin film and their influences on surface morphology and anti-bacterial activity of silver films for water treatment. Int. Nano Lett. 8, 157-164 (2018). https://doi. org/10.1007/s40089-018-0240-8

27. https://www.comsol.com/models/plasma-module. Accessed 10 Apr 2018

28. http://fr.lxcat.net/instructions/. Accessed 12 Nov 2018

29. BOLSIG+, Electron Boltzmann equation solver. https://www.bolsi g.laplace.univ-tlse.fr. Accessed 12 Nov 2018

30. Barjasteh, A., Eslami, E.: Numerical investigation of effect of driving voltage pulse on low pressure $90 \% \mathrm{Ar}-10 \% \mathrm{Cl}_{2}$ dielectric barrier discharge. Plasma Chem. Plasma Process. 38, 261-279 (2018). https://doi.org/10.1007/s11090-017-9849-z 
31. Das, S.P., Dalel, G., Barlk, A.: A dielectric barrier discharge (DBD) plasma reactor: an efficient tool to measure the sustainability of non-thermal plasmas through the electrical breakdown of gases. IOP Conf. Ser. Mater. Sci. Eng. 410, 012004 (2018). https://doi.org/10.1088/1757-899x/410/1/012004

32. Bryan, A.B.: The dielectric constants of argon and neon. Phys. Rev. (1929). https://doi.org/10.1103/PhysRev.34.615
33. Shaer, M.E., Mobasher, M., Gabr, H.: Voltage and current measurements in a variable gap distance helium DBD at atmospheric pressure. In: 31st ICPIG, Granada, Spain (2013)

34. Equivalent Circuit Modeling of DBD. Chapter 4, Thesis, pp. 83-111. http://shodhganga.inflibnet.ac.in/jspui/bitstream/10603 /.../11_chapter-4.pdf. Accessed 25 Nov 2018 